

\section{NATIONAL BUREAU OF STANDARDS}

The National Bureau of Standards' was established by an act of Congress on March 3, I90I. The Bureau's overall goal is to strengthen and advance the Nation's science and technology and facilitate their effective application for public benefit. To this end, the Bureau conducts research and provides: (1) a basis for the Nation's physical measurement system, (2) scientific and technological services for industry and government, (3) a technical basis for equity in trade, and (4) technical services to promote public safety. The Bureau's technical work is performed by the National Measurement Laboratory, the National Engineering Laboratory, and the Institute for Computer Sciences and Technology.

THE NATIONAL MEASUREMENT LABORATORY provides the national system of physical and chemical and materials measurement; coordinates the system with measurement systems of other nations and furnishes essential services leading to accurate and uniform physical and chemical measurement throughout the Nation's scientific community, industry, and commerce; conducts materials research leading to improved methods of measurement, standards, and data on the properties of materials needed by industry, commerce, educational institutions, and Government; provides advisory and research services to other Government agencies; develops, produces, and distributes Standard Reference Materials; and provides calibration services. The Laboratory consists of the following centers:

\section{Absolute Physical Quantities ${ }^{2}$ - Radiation Research - Chemical Physics - Analytical Chemistry - Materials Science}

THE NATIONAL ENGINEERING LABORATORY provides technology and technical services to the public and private sectors to address national needs and to solve national problems; conducts research in engineering and applied science in support of these efforts; builds and maintains competence in the necessary disciplines required to carry out this research and technical service; develops engineering data and measurement capabilities; provides engineering measurement traceability services; develops test methods and proposes engineering standards and code changes; develops and proposes new engineering practices; and develops and improves mechanisms to transfer results of its research to the ultimate user. The Laboratory consists of the following centers:

Applied Mathematics - Electronics and Electrical Engineering ${ }^{2}$ - Manufacturing Engineering - Building Technology - Fire Research - Chemical Engineering ${ }^{2}$

THE INSTITUTE FOR COMPUTER SCIENCES AND TECHNOLOGY conducts research and provides scientific and technical services to aid Federal agencies in the selection, acquisition, application, and use of computer technology to improve effectiveness and economy in Government operations in accordance with Public Law 89-306 (40 U.S.C. 759), relevant Executive Orders, and other directives; carries out this mission by managing the Federal Information Processing Standards Program, developing Federal ADP standards guidelines, and managing Federal participation in ADP voluntary standardization activities; provides scientific and technological advisory services and assistance to Federal agencies; and provides the technical foundation for computer-related policies of the Federal Government. The Institute consists of the following centers:

Programming Science and Technology - Computer Systems Engineering.

'Headquarters and Laboratories at Gaithersburg, MD, unless otherwise noted;

mailing address Washington, DC 20234

'Some divisions within the center are located at Boulder, CO 80303. 


\section{Computer Science and Technology}

NBS Special Publication 500-90

Guide to Contracting for Software Conversion Services

Mark W. Skall

Center for Programming Science and Technology Institute for Computer Sciences and Technology National Bureau of Standards

Washington, DC 20234

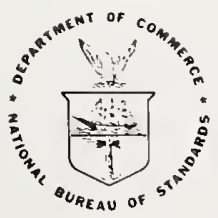

U.S. DEPARTMENT OF COMMERCE Malcolm Baldrige, Secretary

National Bureau of Standards

Ernest Ambler, Director

Issued May 1982 


\section{Reports on Computer Science and Technology}

The National Bureau of Standards has a special responsibility within the Federal Government for computer science and technology activities. The programs of the NBS Institute for Computer Sciences and Technology are designed to provide ADP standards, guidelines, and technical advisory services to improve the effectiveness of computer utilization in the Federal sector, and to perform appropriate research and development efforts as foundation for such activities and programs. This publication series will report these NBS efforts to the Federal computer community as well as to interested specialists in the academic and private sectors. Those wishing to receive notices of publications in this series should complete and return the form at the end of this publication.

National Bureau of Standards Special Publication 500-90

Nat. Bur. Stand. (U.S.), Spec. Publ. 500-90, 67 pages (May 1982)

CODEN: XNBSAV

Library of Congress Catalog Card Number: 82-600531

U.S. GOVERNMENT PRINTING OFFICE

WASHINGTON: 1982

For sale by the Superintendent of Documents, U.S. Government Printing Office, Washington, D.C. 20402 
TABLE OF CONTENTS

Page

1. INTRODUCTION $\ldots \ldots \ldots \ldots \ldots \ldots \ldots \ldots \ldots \ldots \ldots \ldots$

2. CONVERSION PHILOSOPHY $\ldots \ldots \ldots \ldots \ldots \ldots \ldots \ldots \ldots$

3. AGENCY RESPONSIBILITIES PRIOR TO RFP CREATION $\ldots . .12$

4. DESCRIPTION/SPECIFICATION OF SERVICES .......... 34

5. DELIVERABLES AND ACCEPTANCE $\ldots \ldots \ldots \ldots \ldots \ldots \ldots . \ldots 42$

6. INSTRUCTIONS TO OFFEROR $\ldots \ldots \ldots \ldots \ldots \ldots \ldots \ldots \ldots$

7. EVALUATION AND AWARD FACTORS $\ldots \ldots \ldots \ldots \ldots \ldots \ldots$

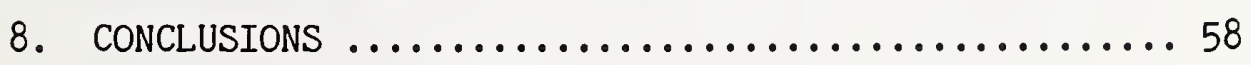

Appendix A: Bibliography and References ...........6 61 

GUIDE TO CONTRACTING FOR SOFTWARE CONVERSION SERVICES

MARK W. SKALL

This guide is the first in a series of publications which will be issued by the National Bureau of Standards with respect to conversion of Federal agency ADP Systems. The need for these publications was determined by a study conducted in 1980, consisting of interviews with commercial conversion experts and Federal Government agency personnel who have recently experienced conversions, as well as a search of the current literature. The results of that study are documented in NBS Special Publication 500-62, entitled CONVERSION OF FEDERAL ADP SYSTEMS: A TUTORIAL. The purpose of this guide is to educate the Federal manager in the benefits which can be gained by contracting for conversion services as well as to specify all the actions the agency must take to ensure a successful conversion contract. The guide concludes that a smooth conversion can be accomplished by thoroughly planning the contractor's activities and effectively communicating these plans to the contractor.

Key words: Acceptance tests; conversion contracting; conversion problems; deliverables; evaluation criteria; Federal agencies; language translators; portability; program inventory; RFP; statement of work.

\section{INTRODUCTION}

The conversion of computer system sof tware is one of the most costly, difficult, and time-consuming tasks associated with the use and maintenance of computer software within the Federal Government. The GAO, in a report entitled MILLIONS IN SAVINGS POSSIBLE IN CONVERTING PROGRAMS FROM ONE COMPUTER TO ANOTHER, [29] estimates that over $\$ 450$ million is spent annually on Federal computer software conversion. The person given the responsibility of managing the conversion effort of ten has no prior experience in 
managing conversions, and the programming staff assigned to the conversion project usually has only a minimal background in conversion. It is unlikely that many of the programming staff participated in a previous conversion at the same agency since the average time between computer replacement in Federal agencies was found to be seven years, which is about double the average tenure of a computer/programmer analyst at a given installation. Additionally, many people on the conversion staff may also lack an intimate knowledge of the software requiring the conversion due to staff turnover since the software was developed. Thus, the general atmosphere surrounding the initiation of a large scale conversion can be filled with anxiety and uncertainty.

Much of the anxiety and uncertainty can be alleviated if the conversion is contracted out to an experienced conversion vendor. Contracting for conversion services may be the only alternative since hiring freezes and personnel ceilings prohibit many agencies from acquiring additional personnel beyond those needed for the regularly scheduled tasks. Thus, with the original implementors long since gone, and documentation frequently inadequate and often out-of-date, a conversion contractor provides the conversion manager with a more optimistic outlook for the future.

A study conducted by the National Bureau of Standards [3] concluded that Federal agency personnel who are involved in writing Requests for Proposals (RFP's) for conversion services are very often confused concerning the type of information that should be included within the RFP, the types of deliverables which need to be specified, and the ways in which to ensure that the conversion has been completed correctly. The report further states that many agencies which have contracted for conversion services in the past have received systems whose performance is inadequate and may not meet the user's needs. This situation of ten results from the agency's reluctance to include performance requirements as part of the acceptance criteria in the conversion RFP. This guide addresses the problem areas cited above and thus gives Federal agency computer managers guidance concerning a large, costly and extremely time-consuming project in which they may have only limited experience.

This guide contains eight chapters. Chapter 1 provides background material on conversion, defines terms, and describes the need for this guide. Chapter 2 describes the different factors which an agency should be knowledgeable in prior to undergoing a conversion. Chapter 3 discusses the role of the agency in conversion. Chapters 4 through 7 describe different items which should appear in an RFP for conversion services, while chapter 8 is a summary of some of the important points brought out throughout the guide. 
Note: Bracketed numbers, i.e. $[\mathrm{N}]$, refer to references in Appendix A.

\section{Definition of Terms}

For the purposes of this guide, conversion is defined to be the process of taking application software in source language from one piece of equipment and modifying it to execute correctly on another piece of equipment, while maintaining the functional requirements of the original software. From the user's viewpoint, the software performs the same functions in the old and new environments. The existing software is referred to as the source program or source system and the converted software is referred to as the target program or target system.

Once the decision to convert has been made, there are a number of conversion techniques which can be utilized. This guide will consider the three following techniques, which are the most widely used: recoding, reprogramming, and redesign. These terms are defined as follows:

* Recoding - Each line of code is translated to an equivalent line(s) of code on the new computer system. This translation can be accomplished manually through visual inspection of the code, automatically through specialized software, or by a combination of the two techniques. From the user's and designer's points of view, the system remains unchanged (with the exception of processing time, which may either have increased or decreased.) One line of code may get translated to many lines of code or many lines of code may get translated to one line of code. The type of transformation that occurs depends upon the source and target languages. Examples are COBOL to COBOL, assembly language to COBOL, and FORTRAN to FORTRAN. If the source and target languages are similar, much of the translation will be one-to-one.

* Reprogramming - Some or all new code is produced. All the code is not translated on a line-for-line basis, but the same functions from a designer's and user's viewpoints remain, along with the same algorithms. Different logic is used to program the same functions, resulting in greater efficiency.

* Redesign - A new system specification is required. The entire design of the system may change, resulting in different algorithms to accomplish the same functions. Different program structure and different logic may be used. New techniques, such as 
database management, may be incorporated, and the structure of program files may change drastically. The new system specification is related to the previous system because the same functions, from the viewpoint of the user, are produced. Changes in the system are transparent to the user.

Why Contract Out for Conversion

Lack of in-house expertise, personnel ceilings, and extremely tight schedules have forced Federal agencies to acquire outside conversion assistance to meet management's demands. There are, however, reasons an agency may want to contract out for conversion services because of the qualifications of conversion contractors. Conversion experience is a skill which must be acquired by participating in a great number of conversions in various programming languages and on a variety of different source and target computers. Companies specializing in conversion employ people with just this mix of experience. Experience of a typical conversion company may very well include Federal agencies and companies of all sizes, ranging from contracts involving one or two programs to contracts involving hundreds, or even thousands of programs. Many large conversion companies have performed conversions in COBOL, FORTRAN, ALGOL, Pl/1, AUTOCODER and other programming languages and have utilized the following hardware: Burroughs, CDC, Honeywell, IBM, NCR, and Univac, just to name a few. Some conversion companies have expertise with data base management and communication systems. Additionally, conversion companies have access to a great number of software tools, designed to speed up and assure greater quality assurance in the conversion process. Some tools that conversion companies utilize are language translators, file comparators, source code reformatters, analyzers which count the percentage of statements executed by test data, and auditing tools which check adherence to agency standards.

Historically, programmers have viewed conversions as an extremely undesirable activity. They are "stuck" with a program that they neither designed nor coded, and now they must get it to execute correctly on a machine with which they may not be familiar. Furthermore, conversion is viewed as being much more mechanical and not nearly as intellectually stimulating as new coding or design. The above problems are compounded by the fact that the natural instinct of most individuals is to resist change, and cling to that with which they are most familiar. Thus, retaining good morale among programmers assigned to conversion projects is, perhaps, an impossible task. The U.S. Navy found that working on conversion contributed to the high attrition rate of civilian employees more than any other activity in the 
Navy's data centers. This factor alone may justify an agency's decision to contract out for conversion services.

The PROVISIONAL CHECKLIST FOR SOFTWARE CONVERSION PROJECTS [32], prepared by the U.S. GENERAL ACCOUNTING OFFICE states that "Contracting (for conversion services) is attractive when: a) skilled specialists will convert for a fixed price, b) conversion by a contractor will leave inhouse staff free for regular tasks, c) experienced conversion specialists with automated aids can complete the conversion more quickly than in-house staff, and d) little need is foreseen to redesign the programs after they are converted." 


\section{CONVERSION PHILOSOPHY}

A Federal agency's philosophy concerning the way to approach and implement the conversion process will have a profound effect on the form and content of the eventual RFP to acquire conversion services. It is important that Federal agencies understand the ramifications of their decisions concerning several important issues which materialize during almost all conversion projects. Furthermore, the failure of Federal agencies to make decisions concerning the topics which will be addressed later in this chapter may very well lead to potential conversion contractors making these decisions for the agency, and incorporating them into their proposal. Since top management in any agency should not delegate that which is their ultimate responsibility, it is imperative that decisions should be made addressing the areas to be discussed below.

\section{Improvements During Conversion?}

Many existing systems of programs in Federal agencies were designed for, and are operating on, computer systems that are fifteen years old and older. Many of these programs use techniques common to second generation computers, such as tape oriented files rather than disc, code which is not modular and contains few, if any, comments, and reliance on operator intervention. Typically, these programs are poorly documented, if they are documented at all. Certainly, an agency faced with converting programs in this state may want to make improvements to them which will, at least, make the programs more readable and maintainable.

Some of the improvements which can be made to programs during conversion are:

* The use of more recent programming methods such as structured programming or modular programming.

* The addition of more descriptive comments. Very of ten, much time is invested, during conversions, in scrutinizing certain sections of the code to determine the logic. This is valuable information once it is captured and should not reside solely in the mind of the person who analyzed the code. Adding comments to the program will prove very helpful the next time someone looks at this section of the code. 
* The replacement of sequential tape files with disk.

* The use of language statements contained within a FIPS standard language with no vendor extensions.

* The use of internal standards for naming conventions.

* The creation of a test plan.

* The creation of test data.

* The creation of better documentation.

* The removal of operator intervention and device dependency.

A conversion effort presents an opportunity to improve the computer system. Writing the RFP to include improvements to the converted programs, such as the ones listed above, should be encouraged by Federal agencies, since they will make the programs easier to maintain and modify after conversion and will make the next conversion, if it is necessary, a much easier task. However, functional changes that will affect the agency's ability to map the output of the converted programs back to the output of the source programs should be avoided. If functional changes are incorporated, it becomes extremely difficult to verify whether or not a system of programs has been correctly converted.

If it is deemed absolutely necessary to make functional changes to a system of presently running programs which are being converted under contract, then these changes should be made by the Federal agency's programing staff and should be thoroughly documented so that these changes can be incorporated into the converted programs after completion of the conversion effort.

Acceptance Testing

When a conversion is being done under contract, how does the agency know that the contractor has successfully completed the effort? Some absolute criteria must be used to make this determination. These criteria are referred to as acceptance criteria. More detail concerning acceptance criteria will be discussed later in the report when details of the RFP are presented. A brief summary of the major aspects of acceptance criteria is presented below: 
* The converted programs must meet design and specification criteria.

* The converted programs must meet processing time criteria.

* The converted programs must meet accuracy criteria.

* The output of the converted programs operating with converted files must equal the output of the source programs and files.

* The output of the converted systems operating with converted files shall equal the output of the source systems and files.

* Documentation must be supplied indicating all programming changes which were made to the structure or the $\operatorname{logic}$ of the programs in the process of converting from the source to the target machine.

* Execution monitoring must demonstrate that a predetermined percentage of the code is actually executed during testing.

Type of Contract

Much of the current literature about conversion advocates fixed priced contracts for conversion products. The argument is that conversion is the only software project which has a concise specification for the products desired. This specification is the source programs themselves, which define the functions which need to be converted to the target environment. If the acceptance tests in the contract are precise and comprehensive, coupled with liquidated damages for failure to satisfy them, a fixed price contract does indeed look very desirable.

The problem with fixed price contracts is that the job must be well enough defined for prospective contractors to be able to make accurate cost estimates for the conversion. Many conversion companies maintain comprehensive data bases for conversion cost estimation. However, these data bases are usually based on using recoding to accomplish the conversion. Recoding only guarantees functionally equivalent source code, not a program which runs efficiently. If performance and efficiency constraints are included as part of the acceptance criteria (as they should be), then the scope of the effort is not known with as much certainty since a great deal of tuning of the code may be necessary in order to meet certain performance and efficiency constraints, such as execution speed and memory requirements. 
Contractors may be compelled to switch to reprogramming or redesign to accomplish much of the conversion. Cost estimates for these methods are much more difficult to make, since these methods can not be automated to the same degree as recoding.

One useful set of criteria that can be used in deciding among conversion techniques was specified in an NBS Special Publication entitled CONVERSION OF FEDERAL ADP SYSTEMS: A TUTORIAL [3], and is listed below:

* Recoding - Source and target languages should be similar. The source and target computers should have comparable hardware/ software capabilities. If recoding is used when hardware/software capabilities are not comparable, then the capabilities of the new computer may not be utilized, often resulting in inefficient programs.

* Reprogramming - Source and target languages are dissimilar (e.g., converting from assembler to COBOL). Line-for-line translation (or recoding), when the source and target languages are dissimilar, may well result in converted code which is much larger than the source code. For example, in a conversion of assembly language to $\mathrm{COBOL}$, assume that the first assembly language statement loads register 1 with variable $A$; the second statement loads register 2 with variable $B$; the third statement adds the contents of register 1 to register 2 ; and the fourth statement puts the new contents of register 2 in variable C. Some translators, performing line-forline conversion, may generate four COBOL statements corresponding to these assembly language statements. In turn, when these COBOL statements are compiled and assembled, they will produce 16 assembly language statements, producing a four-fold code expansion. A good programmer, using reprograming rather than recoding, would produce COBOL code saying "ADD A TO B GIVING C", which would execute much more efficiently.

* Redesign - The source program is many generations old. The design is out-of-date, and the program is poorly structured and documented. The agency desires a more modular, maintainable, and readable program. 
A manager can implicitly specify the appropriate conversion technique by embedding performance requirements into the conversion RFP. In this way, the contractor is legally obliged to address constraints specified in the RFP (such as response time, memory requirements, size of the target program, etc.). The choice of recoding as a conversion technique will of ten fail to result in the target program satisfactorily meeting these performance constraints. In fact, translators, which use the recoding philosophy, have been known to produce an object expansion rate of 10 to 15 times. Thus, if the new computer is six times faster than the old one, the converted programs will execute at about one-half the speed as before conversion. When performance requirements are embedded in the RFP, the contractor is placed in the ideal situation, from the agency's standpoint. The contractor will still attempt to utilize the most economical and timeliest technique possible, but this technique must also meet the performance requirements. Thus, the product that the agency will obtain is the one that is the least costly and most efficient, but also satisfactorily meets minimum performance requirements.

Many agencies fail to include any performance constraints in the RFP, asking instead for functionally equivalent source code. This can lead to degradation in performance, as illustrated in the the assembler to COBOL translation documented above, and may result in a converted system which does not meet the user's needs.

In summary, for a conversion which only needs to be recoded, the scope of work can be precisely defined and acceptable cost estimates can be made. Generally, conversions which have stringent performance requirements can not be accomplished solely by recoding. If stringent performance requirements are specified, then reprogramming or redesign will probably be the preferred method of conversion, and the contract may very well not be fixed price. Remember that the decision concerning the type of contract is determined by the specifications in the RFP. The final selection of the type of contract, however, should be made only after consultation with the Contracting officer.

\section{Maintaining Control Over the Contractor}

GAO, in a report entitled CONTRACTING FOR COMPUTER SOFTWARE DEVELOPMENT--SERIOUS PROBLEMS REQUIRE MANAGEMENT ATTENTION TO AVOID WASTING ADDITIONAL MILLIONS [28], points out that agencies quickly overcommit themselves and fail to control contractors through specific clauses in the RFP. Some methods which can be used to control contractors are: 
* tight contract monitoring,

* strict phasing,

* requiring written progress reports,

* specifying the standards to which the contractor must adhere,

* identifying critical milestones,

* identifying a single focal point for communication,

* conducting audits to verify if deliverables are correct.

Agencies of ten commit themselves to the entire contract without receiving feedback as to whether or not the preliminary phases of the contract are being performed satisfactorily. Smaller pieces of the total system should be identified as critical milestones in the preliminary phases of the contract and a determination can then be made as to whether or not these programs have been successfully converted, before allowing the contractor to continue with the contract. The determination as to whether or not the programs have been successfully converted should include predetermined criteria for the unit test plan and test report, the percent of statements that have been executed during testing and the performance of the converted programs. Written progress reports should be required by the contract in order to keep the agency apprised of progress and the attainment of critical milestones, as well as potential problems.

To improve communications and to eliminate conflicting information emanating from the contractor, agencies should establish a single person as a focal point for communications with the contractor. 


\section{AGENCY RESPONSIBILITIES PRIOR TO RFP CREATION}

Before a contractor can begin a contract to convert a computer system, much work must be done by the agency's staff to produce inputs for the contactor. In fact, agency people who are knowledgeable about the system which is being converted must be intricately involved throughout the conversion effort if the conversion is to be successful.

The most obvious and also the most important task to be done by the agency's staff is the identification of exactly what is to be converted. This task provides agency personnel the opportunity to scrutinize the existing system of programs and to make assessments as to which of these programs are still functional and thus, should be converted.

Identifying what is to be converted is accomplished by taking a complete inventory of all programs, files, data bases and documentation which pertain to the source system. Many conversion authorities advocate using some form of conversion inventory worksheet to identify all the program, file and data base components. Some worksheets recommended by GSA's Federal Conversion Support Center (FCSC) [8] and used by the Department of the Army [15] are shown in figures 1 through 6. Figures 1 and 2 are the FCSC worksheets and figures 3 through 6 are from the Department of the Army. Conversion type in figures 4 and 5 refers to the degree of difficulty involved in converting the file. Type $A$ is the easiest type of file to convert, type $B$ the second easiest, and type $C$ the most difficult type of file to convert. The information required in these worksheets is the absolute minimum needed by the contractor to successfully complete the conversion. We recommend that an agency, which is about to undergo a conversion, examine these sample worksheets and determine whether or not they are sufficient for its needs. If these worksheets are not sufficient, the agency should devise some to meet its needs. Following is a list of items to choose from when developing a conversion inventory worksheet. This list is very comprehensive and may include items not relevant to a particular system of programs. Thus, in devising a worksheet, an agency should include only the items on the list which are pertinent. 


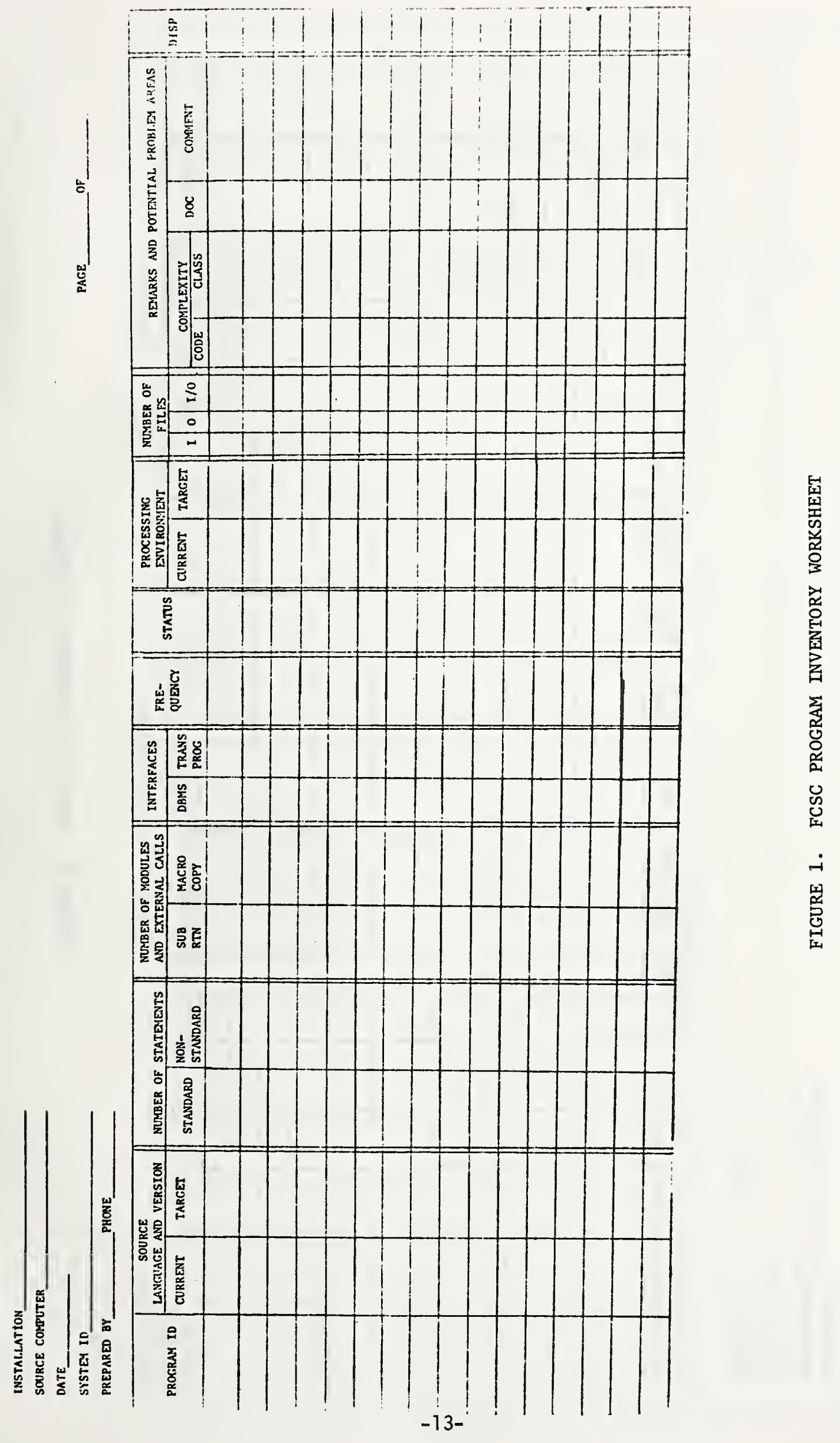




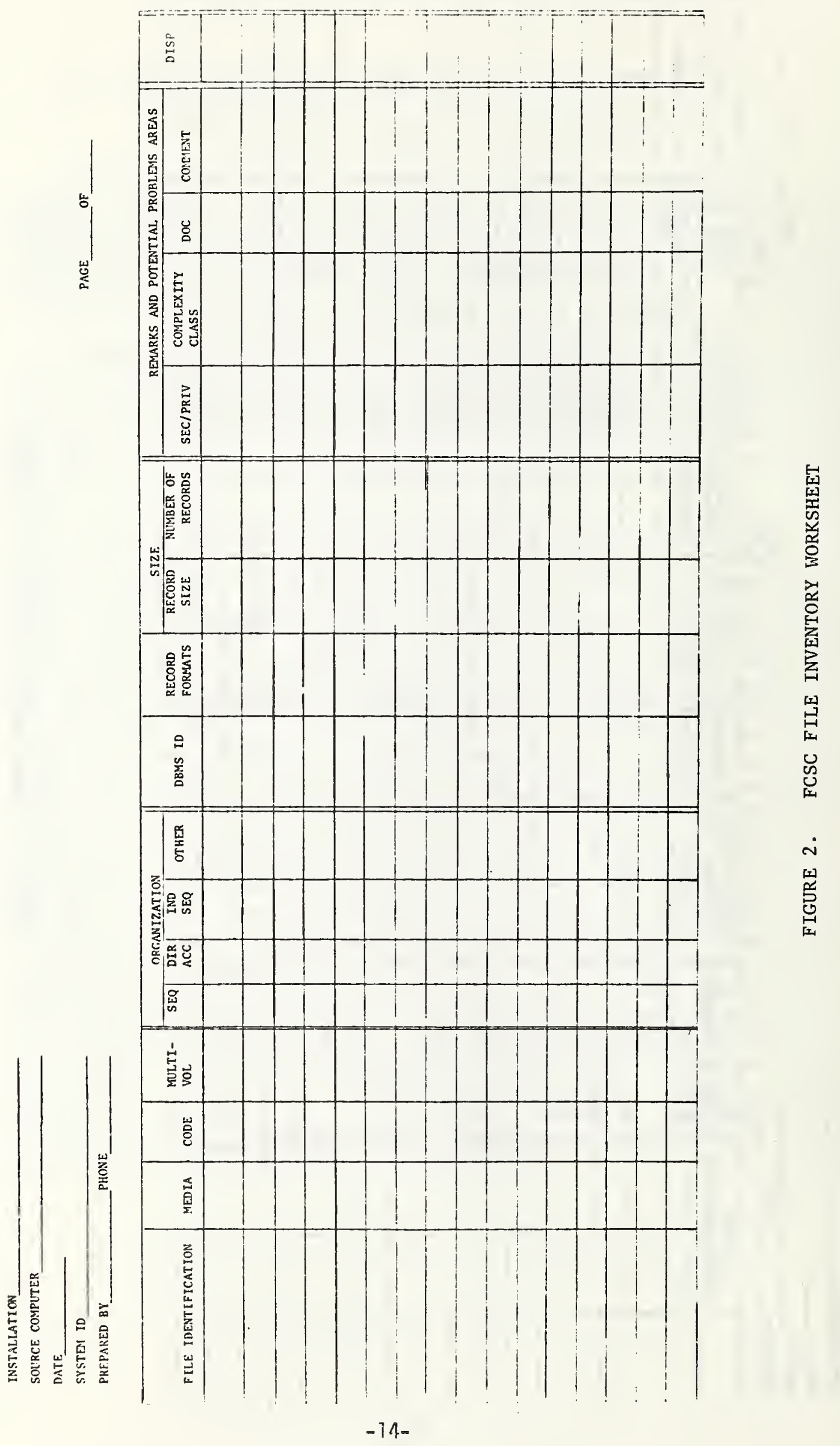


$\mid$

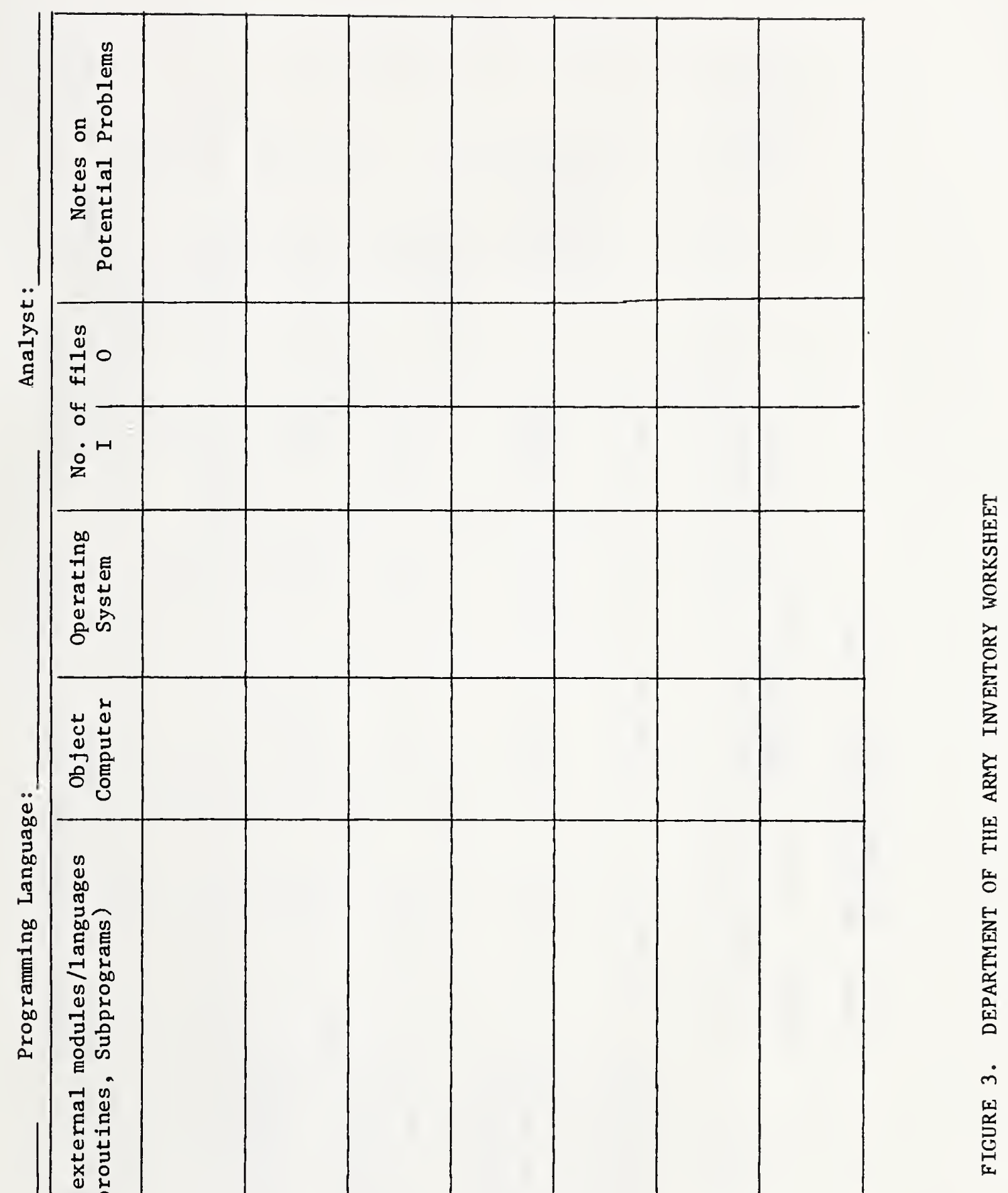




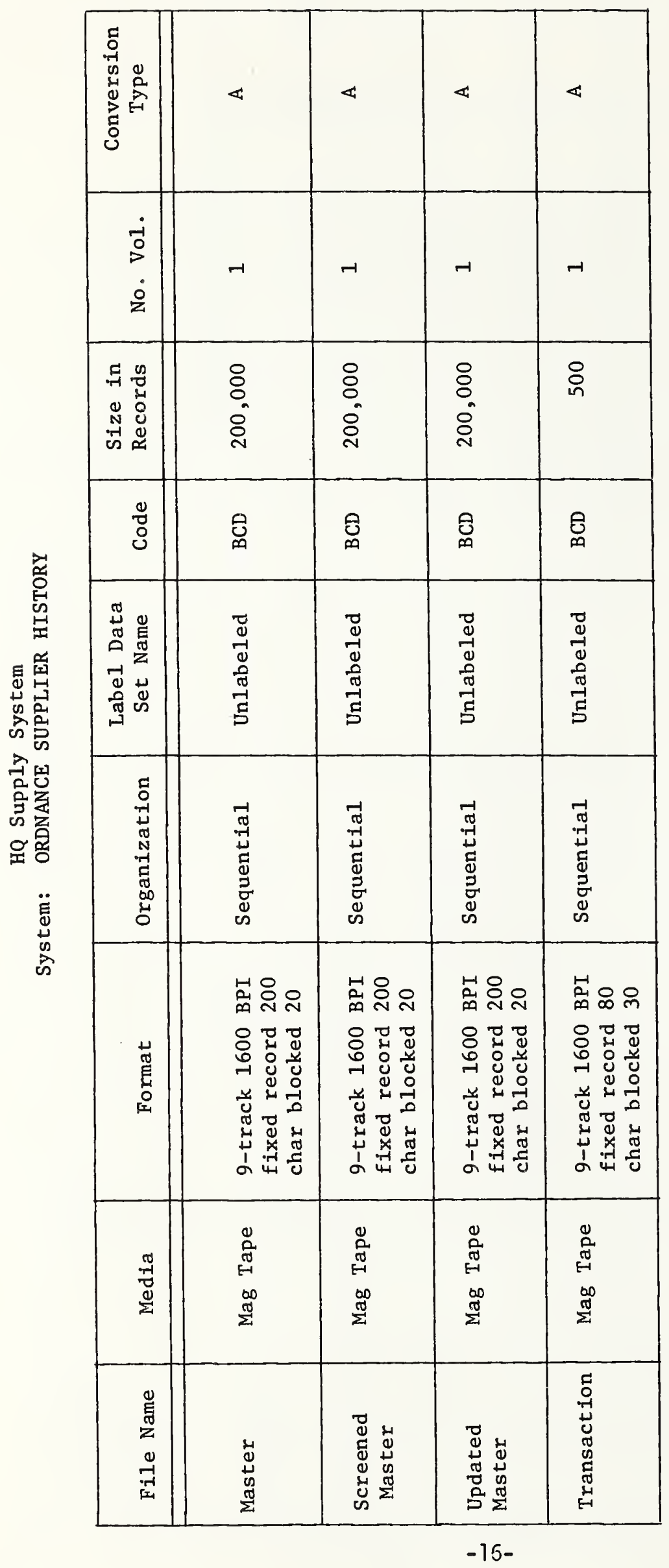

星 


\begin{tabular}{|c|c|c|c|c|c|c|}
\hline 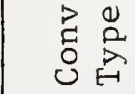 & $\varangle$ & $\cup$ & $\varangle$ & ט & & \\
\hline $\begin{array}{l}0 \\
0 \\
0 \\
0 \\
0 \\
0\end{array}$ & $\dot{\square}$ & 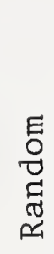 & $\begin{array}{l}\dot{\Xi} \\
\dot{\Xi}\end{array}$ & 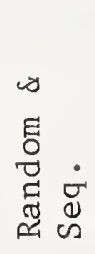 & 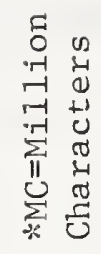 & \\
\hline 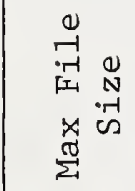 & 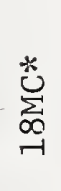 & $\underset{-}{\stackrel{0}{i}}$ & 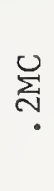 & $\begin{array}{l}\sum_{\infty}^{U} \\
\dot{-}\end{array}$ & $\begin{array}{l}\text { ․ } \\
\dot{N} \\
\text { ন }\end{array}$ & \\
\hline 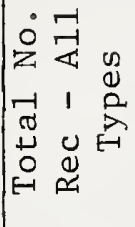 & $\begin{array}{l}8 \\
8 \\
0 \\
0 \\
\infty\end{array}$ & $\begin{array}{l}8 \\
\text { ? } \\
\text { N }\end{array}$ & $\begin{array}{l}8 \\
\text { ㅇํ }\end{array}$ & $\begin{array}{l}8 \\
8 \\
0 \\
\text { a }\end{array}$ & $\begin{array}{l}8 \\
8 \\
8 \\
\infty \\
\circ \\
\circ\end{array}$ & 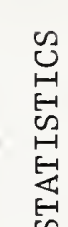 \\
\hline 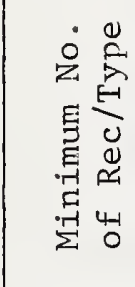 & $\begin{array}{l}8 \\
8 \\
-1\end{array}$ & $\begin{array}{l}0 \\
\infty \\
\infty\end{array}$ & 으 & 으 & $\begin{array}{l}\text { ㅇ } \\
\text { ने } \\
\text { - }\end{array}$ & 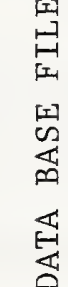 \\
\hline 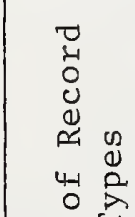 & $\bar{न}$ & $\Gamma_{\infty}$ & $\stackrel{\llcorner}{\sim}$ & เి & $\stackrel{\infty}{\circ}$ & 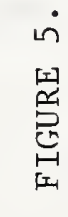 \\
\hline
\end{tabular}


System: Weapons Component Procurement System

\begin{tabular}{|c|c|c|c|c|}
\hline No. & Documentation Component & Complete & Incomplete & $\begin{array}{c}\text { Not } \\
\text { Applicable }\end{array}$ \\
\hline 1 & Application Description & $\mathrm{X}$ & & \\
\hline 2 & System Flow Chart & $\mathrm{X}$ & & \\
\hline 3 & Program Narrative & $\mathrm{X}$ & & \\
\hline 4 & Program Flow Chart/Decision Table & $\mathrm{X}$ & & \\
\hline 5 & Algorithm Description & & & $\mathrm{X}$ \\
\hline 6 & File Layouts & & $\mathrm{X}$ & \\
\hline 7 & Reports & & $\mathrm{X}$ & \\
\hline 8 & Test Data Printouts & & $\mathrm{X}$ & \\
\hline 9 & Program Listings & $\mathrm{X}$ & & \\
\hline 10 & User Instructions & $\mathrm{X}$ & & \\
\hline 11 & Data Preparation Instructions & & $\mathrm{X}$ & \\
\hline 12 & Control Clerk Instructions & $\mathrm{X}$ & & \\
\hline 13 & Run Sheets & $\mathrm{X}$ & & \\
\hline
\end{tabular}

FIGURE 6. DOCUMENTATION REVIEW FORM 


\section{A. System Information}

* System identifier

* Point of contact

* Date the inventory is prepared

* Description of system

* Source computer

* Target computer

* Operating system

* Name and number of all application programs in system

* Total lines of source code of each application program in system

* Name, number and total source code lines of all programs in the system grouped according to the language they are written in

* Name and number of all files in system

* Name and number of all common subroutines in system

* Name and number of all data bases in system

* Name and number of all stand-alone utilities in system

* Name and number of all programs by size: a)Under 1000 lines, b) 1000 - 10,000 lines, or c)greater than 10,000 lines

* Run frequency of the system

* Name and number of all user coded macros

* Interfaces within the system

* Interfaces to other systems

* Description of present DBMS functions and capabilities 
* Identification of general purpose interactive timesharing requirements

* Identification of security and privacy requirements

* Identification of all proprietary packages in the system

* Description of the documentation which exists

B. Program Information - For each program identified in the System Information section, the following should be identified:

* Program identifier,

* Point of contact,

* Date the inventory is prepared,

* Description of program,

* Source language and version (e.g., FORTRAN 66),

* Source computer,

* Target computer,

* Target language and version (e.g., FORTRAN 77),

* Operating system (source and target),

* Number of lines of source code - a)number of lines of standard code, b) number of lines of non-standard code,

* Documentation of existing and potential problems,

* Name and number of all called subprograms,

* Name and number of all input files,

* Name and number of all output files,

* Name and number of all stand-alone utilities used,

* Number of patched statements in object program, 
* DBMS interfaces,

* Telecommunications interfaces,

* Are checkpoint restart capabilities present?

* Does comprehensive test data exist for this package?

* Size of test data (average number of bytes/file),

* Percentage of statements executed by this test data,

* Actual JCL used by the program,

* Description of the overlays used by the program,

* Description of the documentation which exists.

C. File Information - For each file identified, the following information should be supplied:

* File identifier,

* Point of contact,

* Date the inventory is prepared,

* Description of the file,

* Source program(s) that reads the file,

* Source program(s) that writes the file,

* Media (mag. tape, disc, etc.),

* Access method,

* Record format,

* Number of records,

* Average record size.

D. Documentation - The following documentation should be identified:

* User manuals, 
* Local operating manuals,

* Local programing standards and procedures manual,

* Hardware manuals,

* System software manuals,

* Computer manuals,

* Original test plan,

* Program listings,

* Program flow charts,

* Functional specifications,

* Data requirements,

* Design specifications,

* Identification of any deviations from original functional or design specifications,

* Data description,

* Sample input and output listings,

* Sample input data, if it exists, in machine readable form,

* Operator manuals, run books,

* Maintenance manual.

After a complete inventory of all systems, programs, files, data bases, and documentation has been completed, it is very useful to develop cross reference lists between the programming languages used and the types of application software, as well as a program distribution, by language, and a file distribution within each department. The sample charts in figures 7 through 10 [15] may be helpful in this effort. In Figure 9, file types A, B and $C$ describe the conversion difficulty of the file. Type $A$ is the easiest and cheapest type of file to convert. An example of a type A file is a character data file. Type $B$ is more difficult and expensive to convert than type $A$. Type $C$ is the most difficult and expensive type of file to convert. An example of a type $\mathrm{C}$ file is a packed or compressed file with variable record format. 


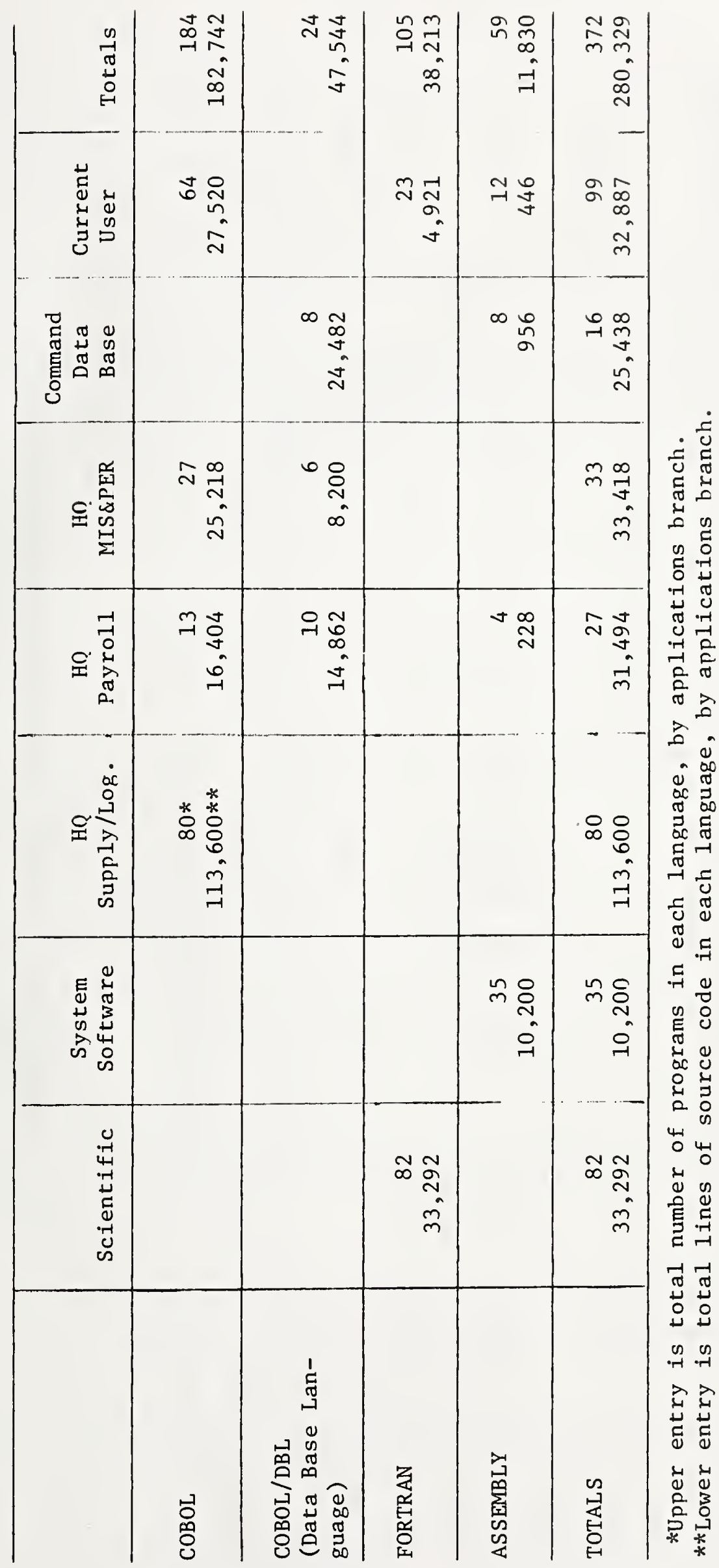

语 


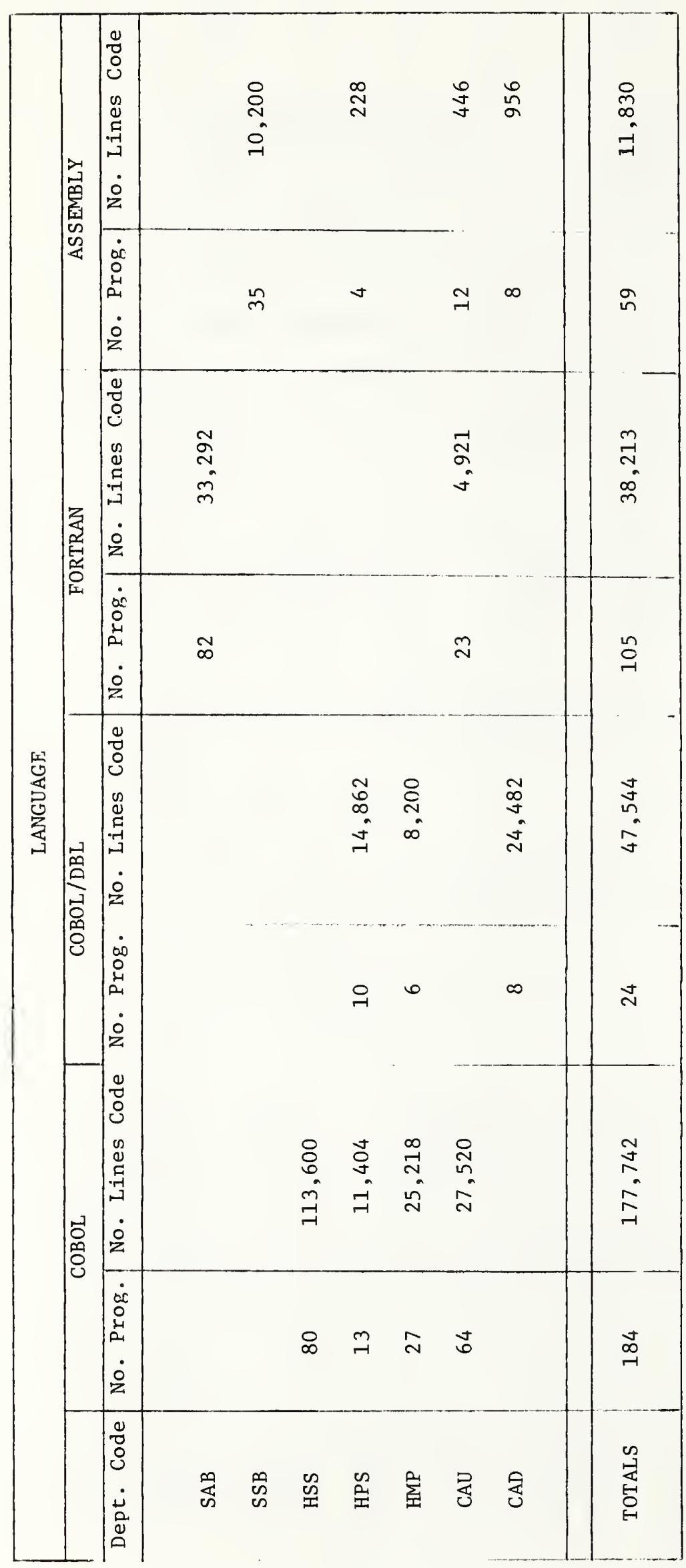

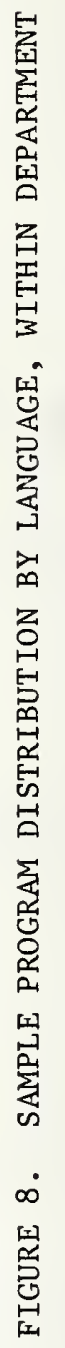




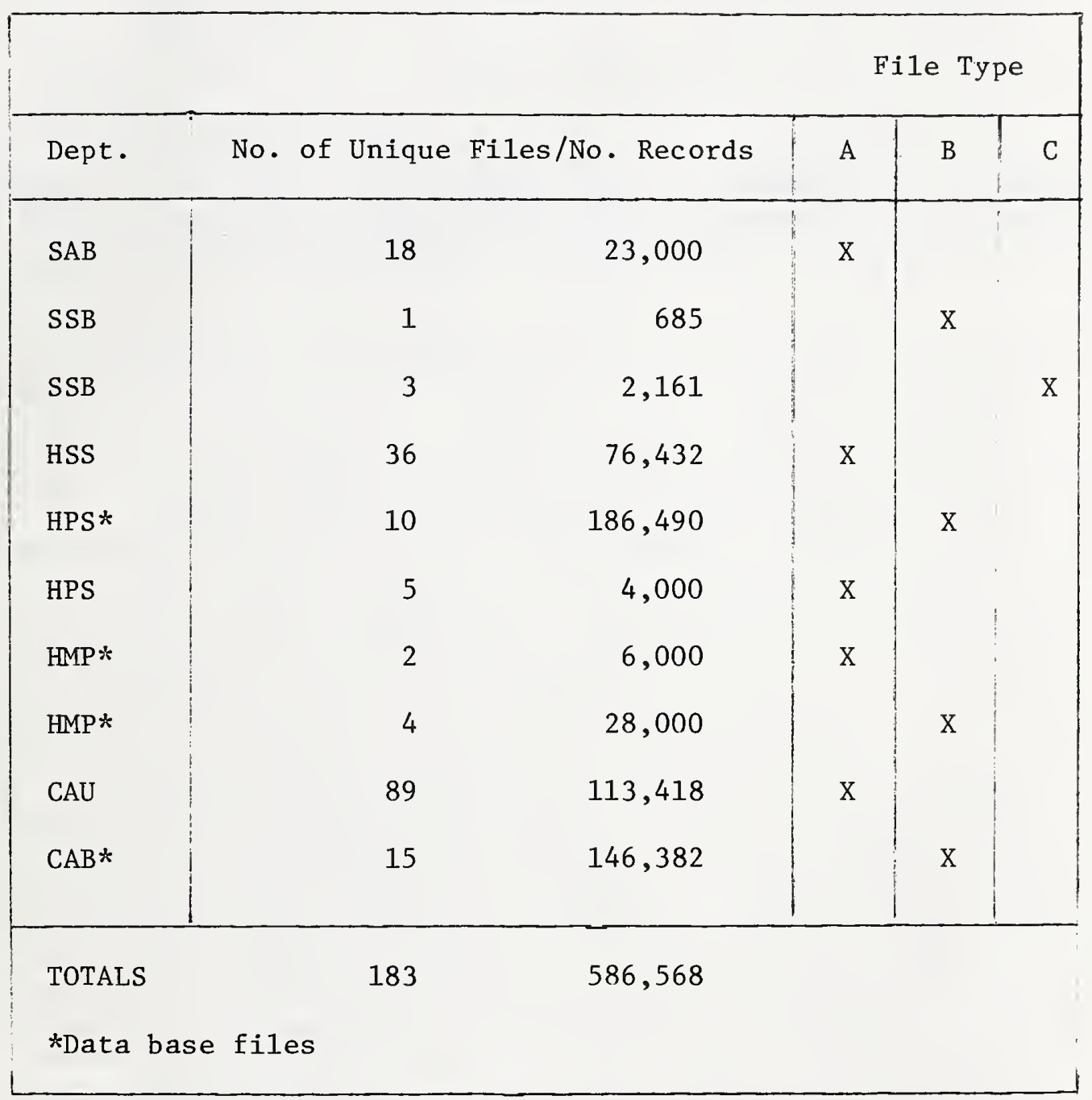

FIGURE 9. SAMPLE FILE SUMMARY: CONVERS ION 


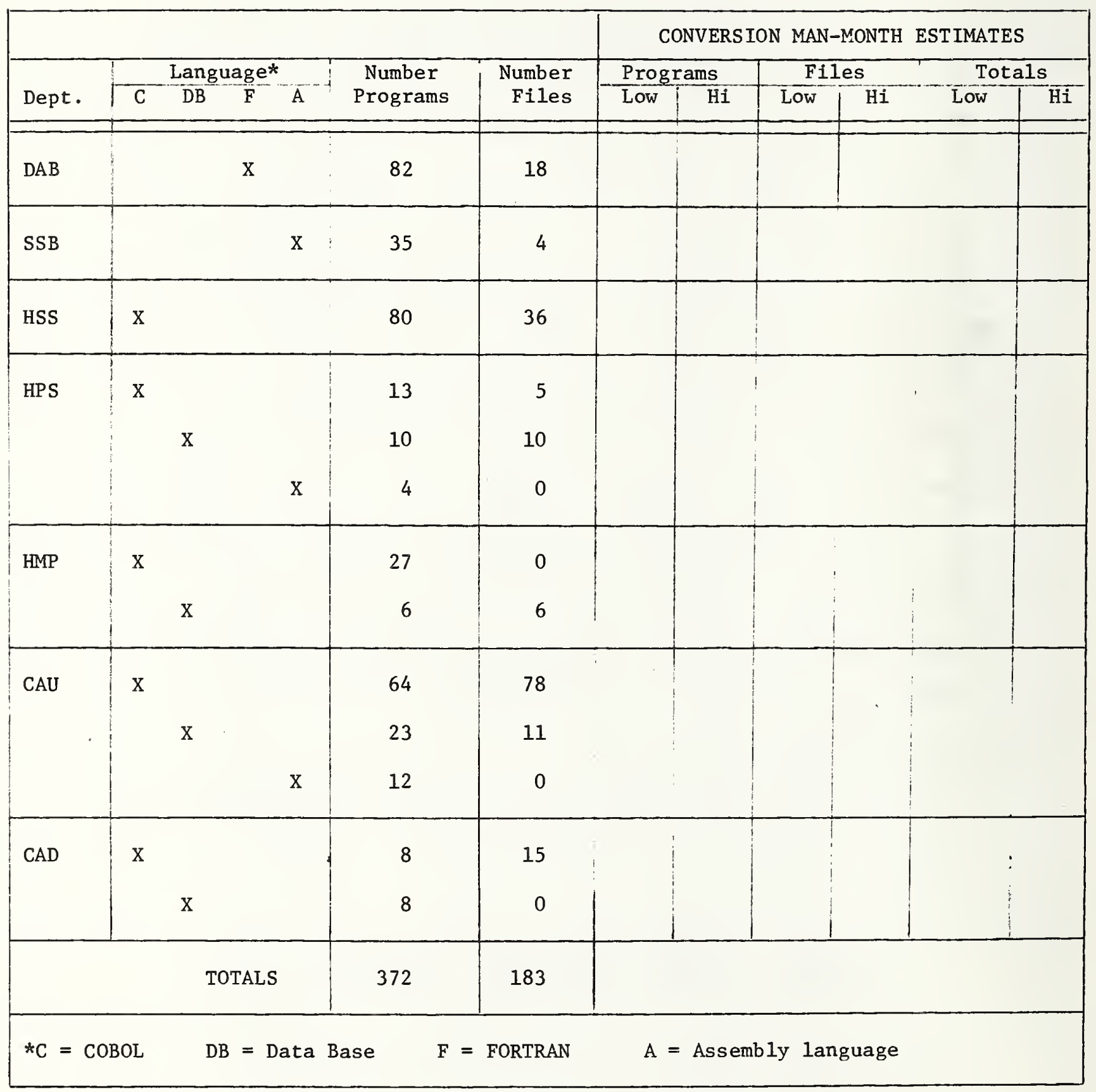

FIGURE 10. PROGRAM/FILE DISTRIBUTION BY DEPARTMENT 
Assessing the Future

After a complete inventory has been taken, decisions can then be made as to the future of all the programs and files identified. This phase of the conversion presents agency personnel with a golden opportunity to "clean up" an existing system. Perhaps, some of the programs or files identified in the various checklists can be "thrown away" (i.e. not converted to the target system) because the functions they perform are not needed anymore. Even if program functions are still needed, usable programs may already exist for the new system which, with little or no additional effort, can reproduce the functions of the old program.

Moreover, the old software may be so poorly designed or inefficient that it should be discarded and new applications written for the system. It may, in fact, be easier to write some new programs from scratch than to convert them to the target system. An assessment should also be made of the future expected life of each program. It may be that certain programs will only be needed for a short time following the conversion. In this case, a quicker, cheaper alternative to conversion (such as emulation or simulation) should be investigated for these programs. If the decision to convert the programs is made, the various conversion techniques identified in chapter 1 should be investigated.

The users should be brought into the process at this stage. They may recommend that certain functions be deleted or modified. If functions are deleted, existing application programs may not have to be converted. Comments should also be solicited from users concerning the existing output. They may recommend that the output should be modified. $\mathrm{Be}$ careful, however, when attempting to modify the output, since it is imperative to be able to map the output of the source system to the output of the target system. It is therefore recommended that changes made to the programs which affect the output be made prior to the beginning of the translation phase or subsequent to the completion of system testing.

The users should also be able to help determine the relative priority of the various application programs, thus helping determine which programs should be converted in the first batch by the contractor. The inclusion of organizational priorities into the RFP will help ensure that the conversion schedule developed will be responsive to the agency's needs, while interfering as little as possible with the existing operation. 


\section{Note Existing Conversion Difficulties}

All programs which have been identified on the program worksheet as having potential problems should now be reviewed in depth to determine the nature of these problems. A program is defined as having no conversion difficulties if it can be converted to another computer by recompiling and correcting only syntax errors. If the program has conversion difficulties, these difficuties should be documented in a separate list. The noted conversion difficulties generally fall into two groups:

1. Extensive logic changes needed which affect the program throughout (e.g., a FORTRAN array which is larger than the new system can accomodate must be redesigned, and the logic to access the array must be rewritten)

2. Code replacement needed, affecting the program in a specific, limited area (e.g., replacing ENCODE/DECODE in FORTRAN with a more widely accepted input/output method)

This detailed list and analysis of potential conversion difficulties will make the contractors' job less costly (since they don't have to determine these problem areas for themselves) and helps assure that these major problem areas are addressed in the conversion. The charts which are described in Figures 11 and 12 [15] may be of help in determining how prevalent potential conversion problems are within the existing code. 


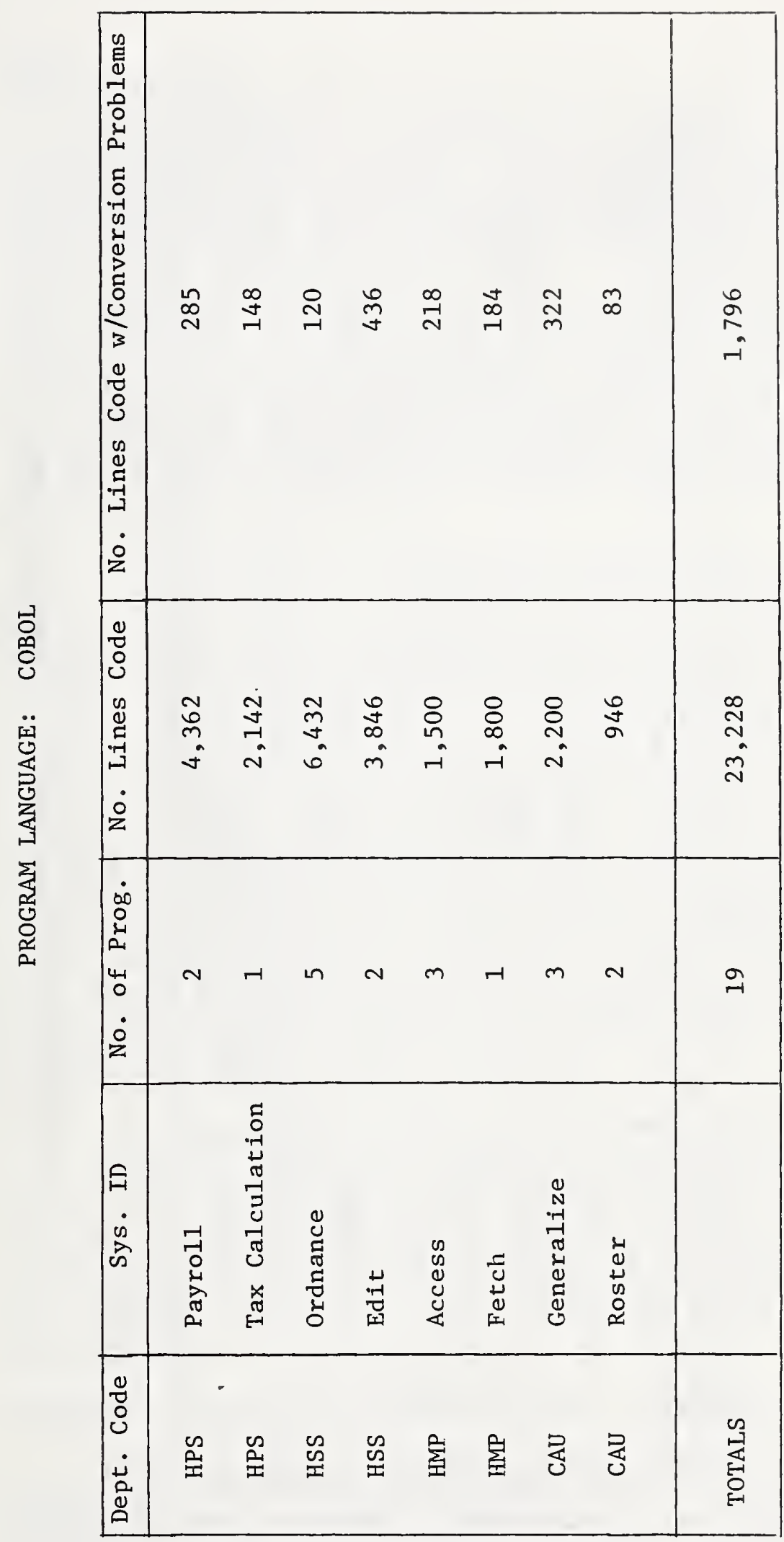

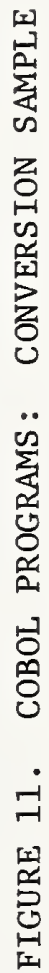




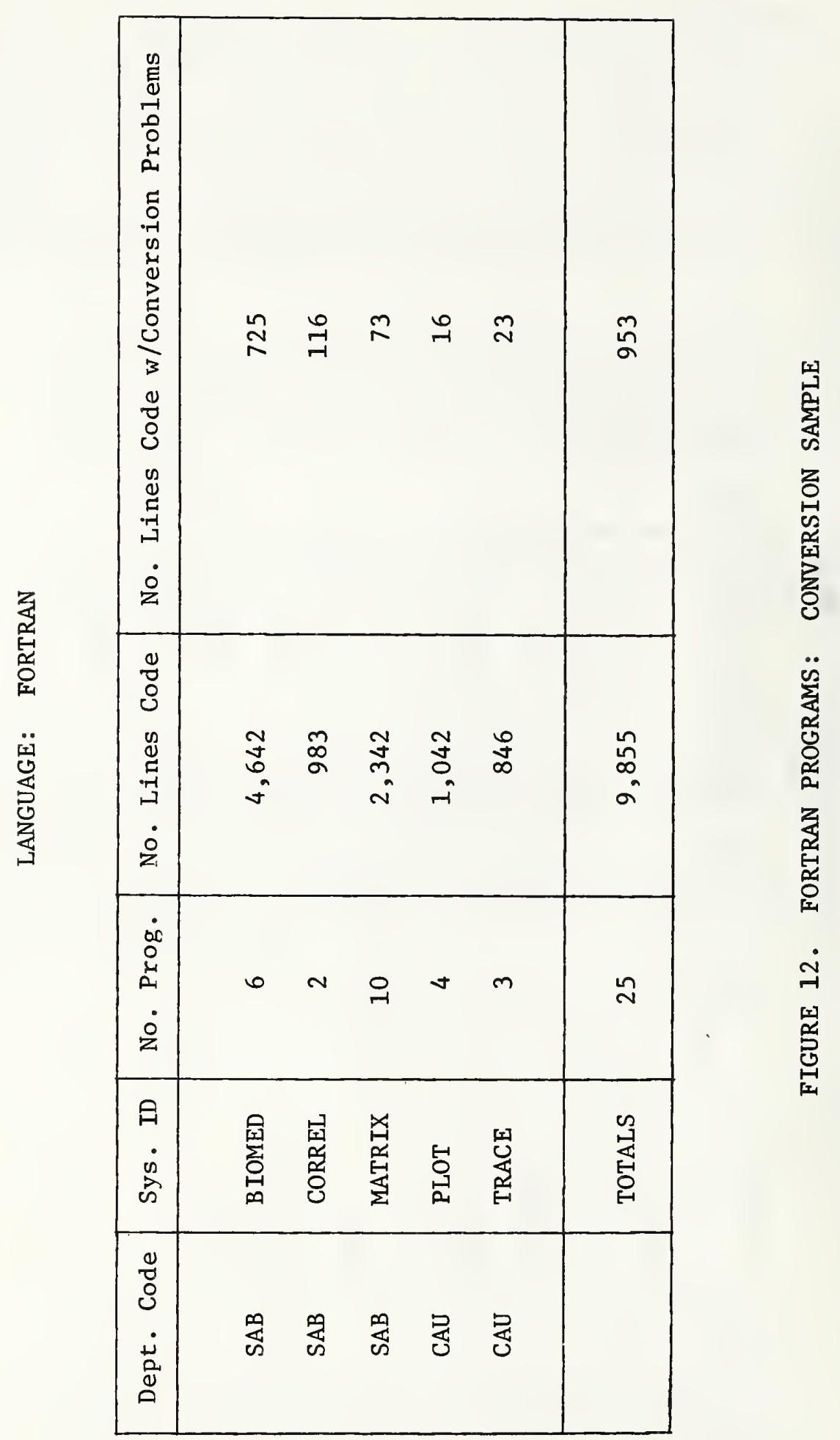




\section{Data Preparation}

Data preparation is the process of gathering all the materials that will be used in the conversion. The agency staff should do the vast majority, if not all, of the data preparation since they are the most qualified to identify the types and sequence of information to gather, and the ways in which to prepare the conversion materials. During data preparation, the agency staff must ensure that all the inputs to the conversion process, (which should have been derived from the conversion inventory worksheet, and modified based on each program's usefulness on the new system) are available to be used by the contractor. These inputs should include program source listings, input files, record layouts, documentation, etc.

Test files must be generated to ensure that the contractor adequately tests and validates the converted system. Thus, test data that can exercise at least 70 percent of the program code should be generated on the source system. Although the study of testing is currently in the research stage, the 70 percent figure is regarded by conversion specialists to be a reasonable rule of thumb. However, the 70 percent figure should be adjusted depending upon the importance of the code tested. If the code is crucial to the operation of a system, test data that exercises 80 percent or even 90 percent of the program code may be appropriate. It is desirable to keep the input data test files as small as possible, while still providing adequate testing. A test file should be small enough to yield acceptable run times for the converted program, and still be representative of data that can test 70 percent of the code. Test data files (as well as listings) are needed for each program identified on the conversion inventory worksheet.

After test files that test an acceptable amount of code are developed, each source program should be recompiled and run with the test files, producing sample output. Later on, during the testing phase of the conversion contract, the contractor will use this sample output as a comparison for the actual output of the converted programs to determine if the programs have been converted correctly, from a functional standpoint.

\section{Determine Manpower and Computer Resource Estimates}

Before an RFP for conversion services can be completed, estimates must be made by the agency as to the resources required for the contract. Specifically, the agency must develop a conversion workload estimate that itemizes the manpower estimate, as well as the computer costs, to complete the conversion effort. Estimating the staff time, 
computer costs, and time necessary to complete the conversion is not an easy task. There is no universal formula for estimating conversion costs, and it is beyond the scope of this guide to develop a comprehensive discussion of this topic. A recent publication by GSA, entitled REVIEW AND ANALYSIS OF CONVERSION COST-ESTIMATING TECHNIQUES [9], addresses this topic.

A useful approach which may aid agencies in determining conversion resource requirements is the development of a prototype conversion. In this approach, a representative sample of the programs to be converted is chosen, along with qualified people to perform the conversion. It is doubtful that in-house people would be available to perform a prototype conversion since a major reason for contracting out for conversion services in the first place is a lack of qualified people available in-house. It may, therefore, be appropriate to include the prototype conversion as the initial task for the ensuing conversion contract, or as a separate preliminary contract. A separate preliminary contract is preferable since the cost estimates derived from the prototype can be used in negotiations with the offerors for the follow-on conversion contract. Reference [21] may be useful in helping to determine these estimates.

Two factors will necessitate adjustments to the parameters derived from the prototype. One is the initial learning phase which will undoubtedly cause the time estimate to be high. The other factor is the interrelationship problems which must be solved when systems are highly interconnected. The prototype may not be representative of system interrelationships, and consequently, the time estimates derived from the prototype would be low. Probably the most critical factors affecting the parameters are the abilities and experience of the people who will perform the conversion. Conversion is likely to be more successful, and accomplished in fewer staff-hours, when performed by people experienced in conversion.

Summary of Functions to be Accomplished Prior to the RFP

In summary, it is imperative that a Federal agency undergoing a conversion perform the following functions, prior to releasing the RFP:

* Identification of what is to be converted - This is accomplished by taking a complete inventory of all programs, files, data bases, and documentation. 
* An assessment of the future of all programs - Decisions may be made to discard programs because they were poorly designed or inefficient and to develop new applications for the target system. Certain programs may only be needed for a short time on the target system and a cheaper alternative to conversion may be chosen for these programs. Users may recommend that certain functions be deleted or modified. Finally, users should also help to determine the relative priority of the various programs.

* A review of existing conversion difficulties - All programs which have been identified in the program inventory as having potential problems should be reviewed in depth to determine the nature of these problems.

* Data preparation - The agency staff must ensure that all inputs to the conversion process are available to be used by the contractor. These inputs include program source listings, input files, record layouts, documentation, etc.

* The generation of test files - The agency should generate test files that can exercise at least 70 percent of the program code. Each source program should be executed with these test files to produce sample output which will later be used as a comparison with the output generated from the converted programs.

* A determination of manpower and computer resource estimates - The agency must develop a conversion workload estimate that itemizes manpower, as well as the computer costs, to complete the conversion effort. 


\section{DESCRIPTION/SPECIFICATION OF SERVICES}

The next four chapters address the content of the RFP for conversion products. Specifically, these chapters point out the kinds of information that should be included in different sections of the RFP. This chapter deals with defining the scope of work. Chapter 5 talks about deliverables and acceptance criteria. Chapter 6 addresses how to specify the instructions to the offeror and chapter 7 discusses evaluation criteria. It must be emphasized that these chapters do not comprise a boilerplate for the information to be contained in an RFP for conversion services. Instead, they contain general guidance concerning the types of considerations a conversion manager is generally faced with. Each agency which is engaged in developing an RFP for conversion services should work with their own procurement department, as well as GSA's Federal Conversion Support Center, to derive the details of the RFP.

The purpose of this chapter is to detail the scope of work which will be performed. The SPECIFICATION OF SERVICES section is the core of the RFP, since this is where the agency specifies exactly what is to be converted and the conditions and constraints that must be adhered to by the contractor. Each section in this chapter addresses a separate area that an agency should include in an RFP to define the scope of work. Prior to the gathering of information necessary for this section, a glossary of terms that are used in the RFP should be developed. The glossary should then be included as a separate attachment to the RFP.

\section{Reason for Conversion}

The agency should first provide background information concerning the goals of the agency, the way in which the source system contributes to these goals, and a functional description of the source system. This should be followed by a detailed explanation of the circumstances necessitating the proposed conversion. An understanding of the reasons for the conversion effort, and an awareness of the goals of the conversion can help the contractor decide upon a general implementation strategy, including the choice of an appropriate conversion technique to use. This information can be included as an attachment to the RFP, rather than embedded in the section which describes the scope of work. 


\section{Current Computer System}

This section should describe both the current hardware and current non-application oriented software. The hardware description should include the manufacturer and model number of the mainframe, primary memory capacity, secondary storage capacity, and a complete description of all peripheral devices.

The software description should include the name and version number of the operating system, the compilers, interpreters, and assemblers available and a description of general purpose system utilities presently used by the source system. In addition, general purpose programs, written and used by in-house personnel, should be briefly described. This information can be included as an attachment to the RFP, rather than embedded in the section which describes the scope of work.

Target Computer System

Both the target hardware and non-application target software should be described in this section. As with the current hardware, the description of the target hardware should also include the manufacturer and model number of the mainframe, primary memory capacity, secondary storage capacity, and a complete description of all peripheral devices.

Similarly, the target software description should include the name and version number of the operating system, the compilers, interpreters, and assemblers which will be available on the target machine, and a description of general purpose system utilities which will be available on the target system.

Charts, similar to the ones listed in Figure 13 [15], can be extremely useful in identifying tasks which need to be accomplished because of differences both in the hardware and non-application sof tware between the current and target systems. These types of charts can be produced by the agency and included in this section of the RFP, or prepared as an attachment to the RFP. The charts can subsequently be expanded by the contractor after the award.

\section{Description of Applications}

The most important item to be addressed when defining the scope of work for a conversion effort is to precisely define the application programs which are to be converted. As was mentioned in chapter 3, a complete inventory of ali programs, files, data bases, and documentation which pertain to the source system should have been taken, prior to writing the RFP. The information derived from this inventory is used to help define the scope of work. 

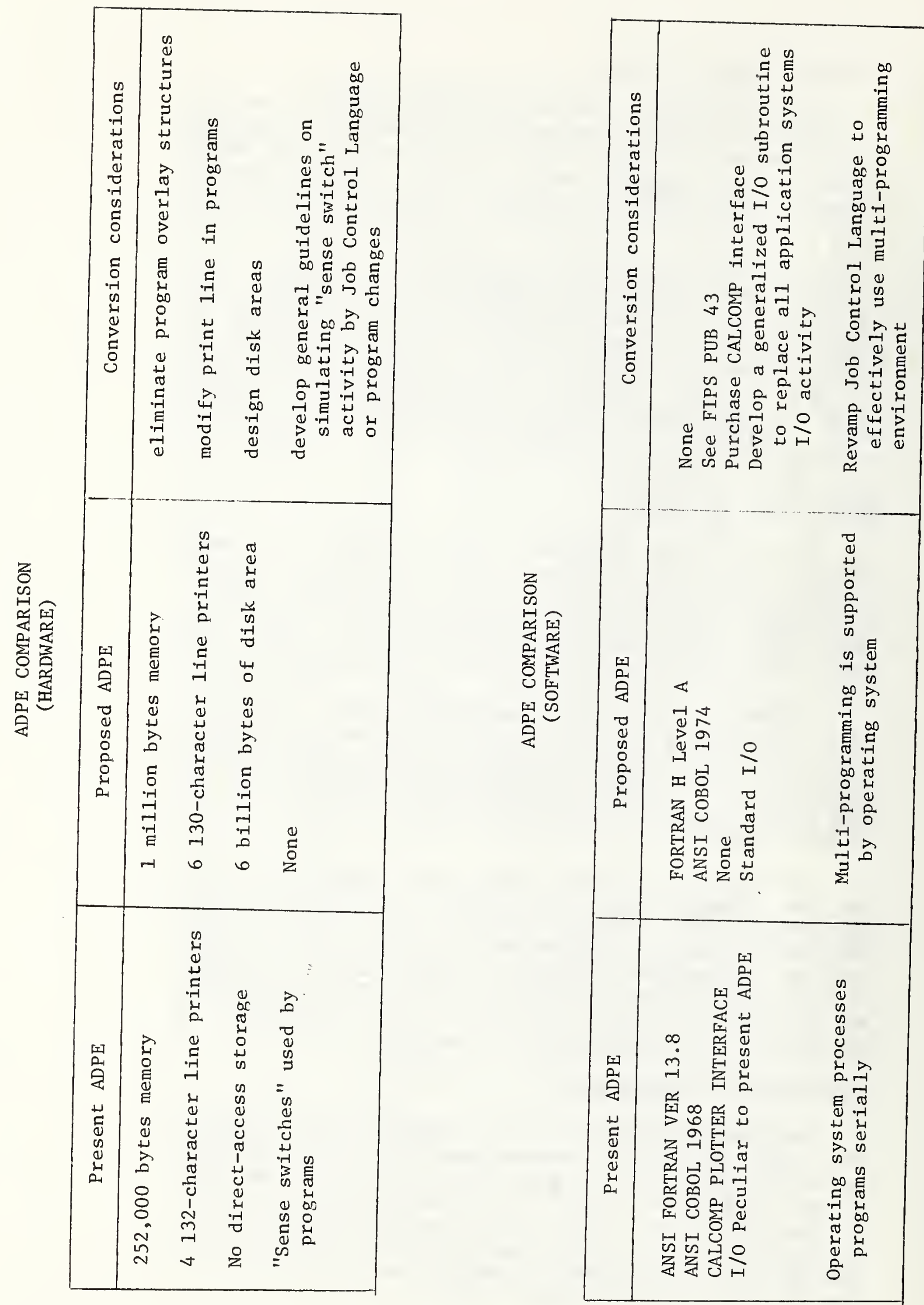
The best way to define the applications to be converted in the RFP is to include the conversion inventory worksheets, described in chapter 3, as an attachment to the RFP. As a minimum, the following information should be provided by the worksheets:

* A description of all programs to be converted. (Figures 1,3,7,8 and 10)

* A description of all files to be converted. (Figures 2,4,9 and 10)

* A description of all data bases to be converted, including a description of source and target DBMS to be used. (Figure 5)

\section{Conditions/Constraints}

In addition to a description of what is to be converted, the Scope of Work needs to define how it is to be converted. In this section, any and all conditions or constraints relating to the methods used by the contractor in implementing the conversion should be discussed.

The first condition or constraint which should be enumerated is the required use of agency standards in performing the conversion. This may include programming standards, documentation standards, or any other standard affecting any aspect of the conversion that the agency wishes to impose on the contractor. The standards which are imposed may be either standards internal to the agency or national standards, such as American National Standards Institute (ANSI) or Federal Information Processing Standards (FIPS), to which the agency may require the contractor to adhere.

Examples of internal agency standards are conventions for variable names or sub-program names, standards for programming style (indentation of certain statements, organization of types of statements with respect to other types of statements) or requirements for programming methodology (the target language code must follow structured programing methodology and must not use any backward goto's, etc.).

An example of national standards which an agency may choose to invoke is the requirement for the target program to conform to the ANSI or FIPS standard for a particular language. This requirement prohibits the contractor from using extensions to the language, provided by the compiler of the target machine, in performing the conversion. According to FIPS PUB 68 (Minimal BASIC) and FIPS PUB 69 (FORTRAN), source programs, whether developed internally or on 
contract should be limited to the elements of the Federal Standard. Nonstandard language features should be used only when the needed operation or function cannot reasonably be implemented with the standard features alone.

Another type of constraint which may be imposed is the requirement for the contractor to use a specific conversion methodology (e.g., recoding, reprogramming, redesign.) Criteria which can be used in helping to determine which conversion technique to use are described in chapter 2. However, unless the agency has a specific reason for requiring a certain technique, the choice of an appropriate conversion technique can be left up to the contractor. Appropriate performance requirements included in the RFP (which will be discussed later in this chapter) may force the contractor into using a specific conversion technique in order to meet a specific performance requirement.

\section{Performance Criteria}

In a report by the National Bureau of Standards [3], the authors concluded that the lack of performance criteria in an RFP can often times result in a converted system that does not meet the users' needs. In the past, the failure of Federal agencies to include performance requirements as part of the conversion RFP and the resultant contract, have forced agency personnel to fine-tune the converted code, after they have received it as a deliverable under the conversion contract. This is not only extremely costly to the agency, in labor hours, but even more importantly it often means that the converted programs can't be used until the fine-tuning is completed. Since this fine-tuning may take a year or more until it successfully results in the converted programs executing according to minimum operational efficiency constraints, the inclusion of comprehensive performance constraints into the RFP can save much time and effort later on.

Some types of performance requirements which may be included in an RFP are processing time criteria, memory and execution time considerations, and accuracy criteria. Performance requirements must be measurable and verifiable. Asking a contractor to ensure that processing time be as fast as possible, for instance, is a meaningless requirement.

Accuracy criteria, in the form of required precision in results of arithmetic operations, will more likely be a major consideration in the scientific, rather than business, community. If precision requirements do exist, they should be specified on an individual basis, so that the contractor is not forced to use excessive storage locations for greater 
precision in all programs, leading to disastrous execution time and memory requirements.

Ideally, functional specifications, which describe user requirements, should exist for all source programs and systems. These requirements should have formed the basis for the design of the original programs. Criteria for processing time for the target system can, and should, be derived from the existing functional specifications since the actual functions of a system should not change during a conversion effort. Processing time criteria are extremely crucial if the system being converted is an interactive, rather than batch, system. An increase of seconds in response time of the converted system compared to the source system can be extremely crucial and may well lead to users being much more reluctant to use the converted system.

\section{Contractor Responsibilities}

CONVERSION OE FEDERAL ADP SYSTEMS: A TUTORIAL [3] lists six major phases of conversion: the planning phase, the data preparation phase, the translation phase, the unit testing phase, the system testing phase, and the parallel testing phase. The contractor performing the conversion has distinct and specific responsibilities relating to each of these phases. These responsibilities for each of the phases should be detailed in the RFP, and are explained in the remainder of this chapter.

The planning phase consists of identifying and documenting computer systems, programs, and data files that operate on the source computer system, as well as deciding how the transition to the new computer system should be made. The RFP should require the contractor to review the agency's work done during the planning phase and provide a schedule for the collection of programs, files, data bases, and documentation, as well as milestones for data preparation, conversion, and unit, system, and parallel testing. In addition, the contractor should be asked to describe, in detail, all tasks that he or she will perform throughout the duration of the contract.

The data preparation phase is the process of gathering all the materials that will be used in the conversion. The information gathered in the planning phase is used to assure that all the inputs to the conversion process (program source listings, input files, record layouts, and documentation) are ready for the conversion. Test data must also be generated in this phase to assure that adequate testing and validation will be performed on the converted system. Generation of test data can be done either by the agency or required of the contractor in the RFP. If the agency staff 
decides to generate the test data, they should make sure that they have a way of ensuring that the test data they have generated executes a predetermined percent of the code. On the other hand, if the test data is generated by the contractor, the RFP can, and should, require the contractor to ensure that the test data executes a predetermined percent of the code. Thus, for the data preparation phase, the RFP should require the contractor to collect all of the inputs to the conversion process and to generate test data either by utilizing existing production files or based on criteria provided by the agency.

In the translation phase, each source program is translated to run on the target machine. The RFP should state that the contractor must convert each source program, by name, to the target machine and target language. The contractor should be made responsible for providing all computer resources, facilities, and conversion tools to be used during this phase.

The objective of the unit testing phase is to compile, execute, and test each target program with its test data, and to match the resultant execution output files with those produced on the source computer. The RFP should require the contractor to test each program at the unit level with a minimum percent code execution necessary for successful testing. If a predetermined percent of the code is not executed, the contractor should be required to revise the test files to achieve the desired code execution.

The system testing phase continues the testing beyond the unit test. The interactions of the various programs which form the system are now tested. In this phase, the job control language commands necessary to execute each system are produced. The programs are compiled and executed as a system. The RFP should require the contractor to test the converted system as a whole, using test data, and to develop all job control statements necessary to execute the system.

Parallel testing begins after system testing is completed. The production job control language commands are prepared and the production files are converted. The system is updated to incorporate production maintenance changes made during the conversion. The programs are compiled and executed, and the outputs are compared to the existing production system. The RFP should require the contractor to provide a plan for parallel testing and implementation, software aids, and training of agency personnel. Optionally, the RFP may want to call for contractor personnel onsite for a fixed period of time to help parallel test and implement the system. 


\section{Warranty}

Some conversion firms offer warranties which guarantee that the converted programs will produce output functionally equivalent to that produced by the source programs. With this warranty, the conversion firm will usually agree to correct errors made by the contractor in converting the programs for a period of either one or two years following delivery of the programs to the agency. The correction of errors is done at no additional charge to the agency. If an agency desires this type of warranty, it must be specified in the RFP. 


\section{DELIVERABLES AND ACCEPTANCE}

The deliverables in a conversion contract should be derived from each of the different phases of conversion. Each deliverable, including its precise form, should be clearly specified in the RFP. These deliverables, besides including actual source code, will also include different types of documentation. This documentation will usually be of two different types: 1) documentation to verify that a certain phase of the contract has been completed (e.g. a document verifying that a specific program was successfully tested, detailing the test data that was used, and citing the percent of the code that was executed) and 2) documentation in sufficient detail to allow the agency to understand how the converted programs differ from the source programs and to allow for future maintenance of the programs.

The suggested deliverables, associated with each specific phase of conversion, are listed below.

Planning Phase

* Schedule for the collection of programs, files, data bases, and documentation, and milestones for data preparation, conversion, and unit, system, and parallel testing.

* A detailed list and explanation of specific tasks, identifying program batches, and start and completion dates.

Data Preparation Phase

* An accounting of all collected materials for each run.

* A description of the test data generated for each program.

Translation Phase

* Listings of each of the translated programs. 
* Any tools or aids developed for the conversion - including all necessary tapes, documentation, etc.

\section{Unit Testing Phase}

* A description of the completed testing of each converted program, detailing the test file used and the percent of code executed by the test data.

* A comparison of the output of the source and target programs, showing identical ouput when utilizing the same input data.

* A discussion of any specific performance requirements for a particular program and an explanation as to how the unit testing phase verifies that the performance requirements are adhered to.

* Any test files developed or modified by the contractor.

\section{System Testing Phase}

* Converted source programs on magnetic tape and converted source program listings.

* Converted job control language commands for each system.

* A description of the completed testing of each converted system, detailing the test file used and the percent of code executed by the test data.

* A comparison of the output of the source and target systems, showing identical output, when utilizing the same input data in the system testing phase. The contractor must identify, and explain, any places in the output where an identical match does not occur.

* A discussion of any specific performance requirements for the system, as a whole, and a justification as to how these requirements are verified in the system testing phase.

* Any test files developed or modified by the contractor. 
* A detailed plan for parallel testing and implementation, as well as necessary software aids, and a plan for training of agency personnel.

* A program which converts all source system input files to a format acceptable to the target machine.

* A file compare routine, developed for the target machine, which will determine the equality of two files, and, thus, help the agency during the parallel testing phase.

Documentation for Understandability

Documentation which helps the programmer understand the logic within a program can be presented in two different ways: 1) either internal to the program or 2) external to the program. Internal documentation takes the form of nonexecutable statements in the language, which serve as comments. The comment line in FORTRAN or the REM statement in BASIC are examples of these types of statements. Making sure contractors supply comments in any programs they are writing for an agency is a must. For a conversion contract, the contractor should be made to supply comments about specific sections of the code which proved exceptionally difficult to convert and any impact that these sections of the code may have on future maintenance and general understandability or readabiltiy. These comments can be cited as deliverables as a product of the unit testing phase.

Program documentation external to the code should also be supplied by the contractor. If acceptance criteria are properly included in the RFP, the contractor may have to do extensive reprogramming, or even redesign to meet the performance requirements. Updated documentation (if program documentation currently exists) or new program documentation must reflect the changes made to the programs for the purpose cited above.

In addition, other types of documentation, designed to help a designer, programmer or user understand the converted system may be asked for, depending upon the conversion method used (recoding, reprogramming or redesign) or the future plans of the agency. The following is a partial list of some other documentation which may be desired by the agency: 
* Operating instructions, including a description of the job control commands used.

* Training documents.

* Data file descriptions.

* Program flowcharts or top down design analysis (only if reprogramming and redesign are required).

* System flow charts (if redesign is required).

* Implementation plan to be used for the remainder of the conversion task.

\section{Acceptance Criteria}

GAO, in a document entitled CONTRACTING FOR COMPUTER SOFTWARE DEVELOPMENT--SERIOUS PROBLEMS REQUIRE MANAGEMENT ATTENTION TO AVOID WASTING ADDITIONAL MILLIONS, [28], states that "Extensive acceptance testing criteria and test data should be developed before the contract is released and acceptance tests contractually required. Test and acceptance criteria--how software must perform before it will be accepted--must be identified."

Acceptance criteria comprise one of the most important parts of the conversion contract. Without adequate acceptance criteria, an agency may spend millions of dollars on conversion and wind up with a converted system which is not usable. Acceptance of the contractor's deliverables and final payment should occur only when the following conditions have been met by the contractor, and verified by the agency:

* All files converted.

* Program outputs equal - The output of the converted programs, utilizing the converted files must equal the output of the source programs, utilizing the source files. The agency should make sure it scrutinizes the output of each converted program for equality, and checks to make sure that a predetermined percent of the program code was exercised by each program during the unit testing phase.

* System outputs equal - The output of the converted systems, utilizing the converted files must equal the output of the source system, utilizing the source files. 
* Documentation updated to reflect changes - If possible, documentation should be required in hard-copy as well as some machine readable medium (computer readable or word processing equipment) so that it can be revised more easily. This documentation should include internal (comments in source code) as well as external documentation, as explained earlier in this chapter.

* Meets design and functional specification criteria Al though this is a conversion effort, rather than an original design, the agency must ensure that any and all design and/or specification criteria that are included are adhered to by the contractor.

* Meets processing time criteria - The agency must designate acceptable parameters for processing time, making it incumbent upon the contractor to choose the appropriate method of conversion (recoding, reprogramming, redesign, etc.) to produce functionally equivalent source code which executes within the constraints set up by processing time parameters. For on-line systems, maximum acceptable response time must be specified by the agency for each set of user interface functions.

* Meets accuracy criteria - This entails specifying an acceptable level of precision for arithmetic operations.

* Meets other performance constraints - This includes run-time efficiency, efficient utilization of main and secondary storage (including proper structuring of data bases, when working in a data base environment), and error checking.

Audits should occur at regular intervals to ensure that these conditions are being met by the contractor. 


\section{INSTRUCTIONS TO OFFEROR}

When preparing an RFP for conversion services, the agency must decide what information is needed from the contractors in order to effectively evaluate their proposals. The instructions to the offerors concerning this type of information should be included in a separate section of the RFP. To the offerors, these instructions specifically describe what they are being asked to do, with respect to the preparation of the proposal.

The information which the offeror is asked to provide will subsequently form the basis for evaluating the proposal, based on the evaluation criteria provided in the RFP. This section of the RFP should contain a warning that insufficient data or inappropriate data may be considered as evidence of a lack of understanding of the intended effort, and will affect the evaluation score.

The following sections of the offeror's proposal are needed, as a minimum, in order to perform a complete evaluation. The offeror should be instructed, in this section of the RFP, to provide the following information:

1) Work Statement - The offeror should be instructed to include the following three areas of discussion in his Work Statement:

i) A discussion of the technical and management problems involved in the conversion, demonstrating a clear understanding of all the issues.

ii) An outline and discussion of a proposed technical approach for accomplishing the conversion. The proposed technical approach should include a proposed Implementation Plan which identifies tasks to be accomplished, along with projected completion dates. The offeror should provide a detailed explanation and description of the proposed methodology to be used, including a description of which conversion technique(s) (recoding, reprogramming, redesign) will be used for each program or group of programs, and an explanation of why that particular technique is most effective for these programs. The offeror should identify any automated conversion aids that are presently available, or that may be developed for this contract. The description of the automated tools should also provide an indication of the effectiveness of that particular tool (i.e., the percentage of manual coding that remains after utilization of the tool.) Finally, the offeror should submit a proposed test 
plan, which describes the methodology for ensuring satisfactory program design and testing, including quality assurance.

iii) A discussion of the phasing for the contract, based upon the technical approach being proposed.

2) Offeror Experience and Capability - This section should include sufficient information to permit evaluation of the previous and current experience and effectiveness of the offeror in similar or related work, and to demonstrate the offeror's current capability for carrying out the intended contract effort.

At a minimum this section should include:

i) Previous conversions performed by offeror, describing the source and target systems, including a discussion of the scope and complexity of the conversion effort.

ii) Principal clients served in performing these conversions, including pertinent dates, contract numbers, approximate cost, sponsor contact (name, organization, telephone number, and address), and offeror's key personnel involved.

iii) Level of involvement of planned subcontractors under the proposed contract, including sufficient detail to permit overall evaluation.

iv) Brief overall capability identification of offeror.

v) Identification of prospective supporting units or facilities which may be utilized in accomplishing the proposed effort.

3) Proposed Contract Key Personnel - This section should include such information necessary to permit evaluation of the quality, competence, and experience of the personnel proposed to be available for the performance of the intended contract effort. The offeror should be required to provide, for each prospective key person, a resume which includes, at a minimum:

i) Name,

ii) Title,

iii) Brief description of previous work experience (dates, duties, and employers), indicating whether the experience was managerial or technical, 
iv) Detailed statement of previous experience relevant to the intended effort and of recent and current work experience. (Names, current telephone numbers and addresses, where possible, of supervisors or others with direct knowledge of individual's effort and of technical sponsors should be supplied),

v) Specific capabilities, such as programming languages and computers used,

vi) Education,

vii) Publications, patents, and other presentations (a copy to be supplied, upon request, of any listed reference not otherwise readily available),

viii) Labor category and relative percentile salary level within category,

ix) Proposed level of effort availability.

4) Certification - If any proposed Contract Key Personnel are not presently employees, the offeror should be informed that he or she must be involved in current good faith negotiations with prospective employees whose resumes have been submitted and that the offeror has ascertained that the applicant will be available to work under the proposed contract. The offeror should also be asked to provide updated information during negotiations and prior to award when any proposed Contract Key Personnel are no longer available.

5) Technical Management Plan - The offeror should describe the organization and management plan which will be utilized for the technical management of the proposed contract. This description should demonstrate an understanding of the nature of the proposed effort and its potential problems, and how issues will be handled in a timely manner at the proper level of authority. The plan should include the following:

i) A staffing plan indicating how the proposed key personnel will be assigned and the disposition of their time between the proposed contract and other work in progress.

ii) A clear and complete description of lines of activity; interaction with the Contracting Officer's Technical Representative (COTR); and control of scheduling of tasks, reports and other activities.

iii) Identification and discussion of real or apparent possible sources of conflict of interest, that is, a situation which may diminish the offeror's capacity to give 
impartial, technically sound, objective assistance and advice. The term "of feror" in this subparagraph includes any staff, subcontractors, consultants, or any others connected with the offeror who may influence the proposed contract results. The proposal should also identify and discuss planned efforts of the offeror to minimize the effect of any conflict of interest. The offeror should provide updated information during negotiations and prior to award, if any changes are appropriate.

iv) A description of the project management and control tools and techniques proposed and the effectiveness of such tools.

6) Modifications - Any proposed modifications of the proposed contract as described in the RFP should be specifically itemized and discussed in this section. These modifications may differ in technical approach, level of effort proposed, and/or period of performance as long as all the requirements and deliverables of the solicitation are met. 


\section{EVALUATION AND AWARD FACTORS}

Once the offerors prepare their proposals, based on the instructions given to them, the information they have provided becomes the basis for evaluating the relative merits of their proposals. Thus, the evaluation criteria, which are discussed in this chapter, are derived from the instructions given to the offeror. In the remainder of this chapter, suggested evaluation factors are discussed, and a suggested weighting factor is assigned to each. The weighting factor indicates the relative importance associated with each of the factors during evaluation.

Technical Approach to the Statement of Work

The information provided by the offeror in the Work Statement is the first area to be considered in evaluating the propcsal. The technical approach to the statement of work is the section of the proposal where most of the crucial information is obtained and consequently deserves to have a high weighting factor assigned to it. It is in this section where the agency should discover if the offeror actually understands the work involved and if the offeror has the capability to do the job.

When scoring each section of a proposal, it is usually helpful to have a checklist of sub-factors, pertinent to the area, to help decide how many points to assign to each offeror. For the sake of completeness, the of feror should address as many of the factors in the checklist as possible. However, the of feror should not be guaranteed a good score just because all of the factors cited below have been addressed. Quality is still the most important criteria in scoring the proposal. Therefore, the content of the offeror's response concerning the areas in the checklist, and whether or not the offeror demonstrates an understanding of the intended effort and the ability and willingness to perform the conversion are more important than the number of sub-factors that are addressed in his proposal. The following checklist is proposed for helping to evaluate the technical approach to the statement of work:

* Conceptual soundness of approach.

-The overall approach should make sense and should be an appropriate approach for this particular system of programs. 
* Schedule and plan to implement the approach.

-The major phases of conversion should be identified by the offeror.

-The correct activities should be planned for these phases.

* Identification of conversion planning elements.

-The offeror should demonstrate an understanding of what is involved in the planning phase of conversion.

-A comprehensive conversion plan should be presented by the offeror.

* Degree of use and quality of conversion aids proposed.

-The offeror should identify the conversion aids to be used.

-The offeror should also identify the effectiveness of these conversion aids (i.e., the percentage of manual coding that remains to be done after utilizing the tool).

* Offeror's approach to translation.

-The offeror should present a detailed explanation and description of the proposed methodology to be used, including a description of which technique(s) (recoding, reprogramming, redesign) shall be used for each program or group of programs, and an explanation as to why that technique is most effective for these programs.

-The offeror should discuss how non-standard code will be treated and whether or not I/O and nonstandard code will be modularized.

* Offeror's approach to quality control.

-The offeror should discuss quality control for incoming materials as well as quality control during the translation phase.

* Offeror's testing philosophy.

-A comprehensive test plan should be presented by the offeror. 
* Acceptance testing and verification.

-Detailed acceptance tests should be proposed by the offeror.

-Performance considerations should be taken into account by the of feror.

The offeror's philosophy of implementation is among the most important information contained in an offeror's statement of work. The following factors concerning implementation philosophy should be taken into account in scoring the offeror's technical approach to the statement of work:

* Maintainability of converted code - This factor concerns the quality of the converted code.

-Will the code be readable and maintainable?

-What types of standards will be used, besides the ones provided by the agencies?

-How does the offeror view comments and the need for program documentation?

* Training.

-The offeror should discuss plans for training of both his or her staff and the agency staff.

-Specifically, training for programmers, analysts, operators, users, and management needs to be discussed.

* Understanding of and approach to problem areas - The offeror should address the following questions:

-How will distinct differences in computer architecture affect the conversion?

-Will problems arise because of different word sizes on the two machines?

-If so, how will these be handled?

-Will problems arise because of different collating sequences?

-Will differences in JCL cause special problems? 
-Will differnces in primary, as well as secondary memory between the two machines cause problems?

-If so, how will these problems be handled?

-How will machine dependencies in the source code be handled?

-Is program documentation sufficient to address some of the above problems?

\section{Qualification of offeror}

In this section of the proposal, the offeror details the experience of the firm and corporate management, excluding a detailed profile of key personnel. This section, as well as the section on key personnel, is extremely critical in evaluating the proposal because the success of a computer system conversion depends heavily on the experience of the entity performing the conversion. Thus, a high weighting factor is suggested. Comprehensive, detailed experience in conversion is difficult to find since conversions occur infrequently (once every five to seven years), and the people who perform the conversions frequently move on to other areas in data processing, such as design or original programming. Firms which specialize in conversions and who maintain people who build up an expertise in this discipline are in great demand. Previous conversions, performed by the offeror, should be as similar to the conversion addressed in this RFP as possible.

The following checklist is proposed as an aid in helping to score the qualifications of the offeror and/or subcontractor:

* The degree of general experience in software conversion - The offeror should provide details of similar previous conversions performed, describing the scope and complexity of the effort, the source and target systems, and the principal clients served in performing these conversions. References should be checked.

* Specific experience in target language or machine The offeror should describe experience in converting systems to the target language specified in this solicitation as well as to the target computer specified in this solicitation. 
* The available facilities - The offeror should describe the facilities which will be used to perform this conversion and specify how these facilities were utilized in performing other conversions.

* Level of management participation in the corversion process - Since the major difficulties associated with conversions are very often management rather than technical problems, the offeror should demonstrate the conversion management expertise which is retained by the firm.

* Variety of conversion experience - Although not as important as the other factors, a variety of experience will allow the contractor to make difficult decisions concerning unexpected problems, based, in many instances on similar instances in prior conversions.

* Corporate resources - Although larger doesn't always imply better, the of feror must demonstrate that sufficient technical and managerial staff are available to do the job.

\section{Qualification of Proposed Key Personnel}

In this section of the proposal, the offeror details the experience of the key personnel. Competent, experienced conversion specialists are extremely difficult to find. Thus, this section of the proposal must be scrutinized very carefully to determine whether or not the key personnel are actually qualified. A high weighting factor is suggested for Qualification of Proposed Key Personnel.

The following checklist is proposed as an aid in helping to score the qualifications of the key personnel:

* Relative experience of project team - The offeror must demonstrate that the project team has competence and experience to perform the conversion. Specific capabilities, such as programming languages utilized, conversion tools utilized, and computers worked on should be detailed in this section. A complete employment history, including relevant current and recent work experience, project names, descriptions and degree of involvement, and clients should be provided here. References should be checked. 
* Mix of skills of proposed personnel - The offeror must demonstrate that the project team has a sufficient mix of skills to cover the broad areas involved in the different phases of conversion.

* Relative experience of project manager - The project manager is the most important of the key personnel proposed. He or she must possess a broad background of managerial experience in past conversion projects as well as enough low-level conversion expertise to make decisions affecting the technical direction of the project.

\section{Reasonableness of Management Plan}

In this section, the offeror describes the organization and management skills which will be utilized for the technical management of the proposed contract. Management skills involve staffing, scheduling, reporting, managing personnel, and controlling materials. This description should demonstrate how issues will be handled in a timely manner, at the proper level of authority. A relatively low weight is recommended for this factor. The following checklist is proposed as an aid in helping to score the reasonableness of the management plan:

* A staffing plan indicating how the proposed key personnel will be assigned, and the disposition of their time between the proposed contract and other work in progress must be provided by the offeror.

* A detailed schedule, which is consistent with both, the goals of the conversion, as well as the limitations of the conversion effort should be provided by the offeror.

* Responsible management officials must be named.

* Lines of activity and responsibility must be clearly and completely described.

* Interaction with the Contracting Officer's Technical Representative must be detailed.

* Reporting dates and methods should be given.

* Milestones should be clearly identified. 
* The offeror should demonstrate his or her ability to respond on short notice.

* The offeror should demonstrate his or her flexibility to respond to changed conditions.

* Conflicts of interest should be discussed by the offeror.

* A description of the project management and control tools and techniques should be provided by the offeror.

$\underline{\text { Cost }}$

If the contract is fixed price, the agency has determined that the RFP precisely defines the scope of work. In this case, the responsibility is on the contactor to deliver a converted system according to specifications. Since the agency is contractually assured of a correct converted system, regardless of which offeror is selected, the least costly offeror becomes very attractive. Conversely, the determination that a cost plus contact is needed, implies that the scope of work is not as precise, and the agency is depending upon the contractor's best efforts to perform the conversion. In this case, the quality of the contractor is more important than the cost. Thus, a relatively low weighting factor is suggested for cost with the assumption that the contract will be some sort of cost plus contract (cost plus fixed fee, cost plus incentive fee, etc.). If it is decided that the contract shall be a fixed-price contract, then the weight associated with the cost factor will have to increase significantly, and the weight for the other evaluation factors identified must decrease proportionately.

However, as stated earlier, many conversions do not lend themselves to fixed price contracts since the scope of the effort is not known with great certainty, especially if performance and efficiency constraints are included as part of the acceptance criteria. In this case, cost should be a relatively smaller factor than the other factors identified, since the selection of a low cost, but only marginally qualified technical proposal may very well result in a converted system which does not meet the agency needs, and is thus, unusable as it stands. Much expenditure of agency resources, in both manpower and cost, would then be necessary in order to tune the converted system to the point where it would be usable. In the long run, this approach would not only be highly detrimental to the agency's goals and needs, but would actually result in a conversion which is more costly, over its systems life cycle. 


\section{CONCLUSIONS}

Probably the most important thought to keep in mind when writing an RFP for conversion services is to include, in the RFP, everything that you want the contractor to do. Don't assume that anything will be done if it is not specifically stated in the RFP. Avoid the pitfall of having to rely on the contractor for follow-on work because the deliverables have not been sufficiently thought-out and specified. Only close attention to every detail of what should be in the RFP can assure a successful conversion effort. This chapter presents a summary of the most crucial aspects of the RFP.

\section{Specification of Services}

In this section of the RFP, all software which is to be converted must be precisely defined. There is no easy way to accomplish this. A complete inventory of all programs, files, data bases, and documentation must be done and the results from this inventory included as an attachment to the RFP. Any constraints which the agency would like to impose on the contractor must be stated explicitly.

If a specific conversion technique is not required by the RFP, the contractor will almost surely choose to perform a line-for-line conversion since this is the easiest and least costly method. Similarly, if the RFP does not specify performance criteria, the contractor will probably choose to perform a line-for-line conversion since there is no incentive to improve the operating efficiency of the system. Even if perfomance criteria can not be derived and, thus, are not included in the RFP, there may be another reason for asking for reprogramming or redesign rather than a linefor-line conversion. Especially when converting from assembly language to a higher level language, such as COBOL, a line-for-line conversion will result in converted code which is much larger than it should be.

\section{Deliverables and Acceptance}

The deliverables associated with each phase of conversion and the acceptance criteria must be explicitly stated. Minimum acceptance criteria include:

* All files converted, 
* Program outputs equal,

* System outputs equal,

* Documentation updated to reflect changes,

* Meets design and functional specification criteria,

* Meets processing time criteria,

* Meets accuracy criteria,

* Meets other performance constraints.

\section{Instructions to offeror}

The instructions to the offeror should request all information which is needed in order to evaluate the offeror's proposal. These instructions should address the following areas:

* Work statement,

* Offeror's experience and capability,

* Proposed contract key personnel,

* Certification,

* Technical management plan,

* Modifications.

\section{Evaluation and Award Factors}

The choice of evaluation factors and the weight assigned to them are very important since this choice will ultimately decide which offeror receives the contract award. The suggested evaluation factors are:

* Technical approach to the statement of work,

* Qualification of offeror,

* Qualification of key personnel, 
* Reasonableness of management plan,

* Cost.

Conversion contracting can be an experience which is weighed down with problems if it is not well thought-out. Many problems can be avoided, and a smooth transition to the target machine can be accomplished, by thoroughly planning the contractors' activities and effectively communicating these plans to them. An agency cannot expect to receive anything which is not clearly specified in the contract. 
Appendix A: Bibliography and References

1. A study for The FY76 Worldwide ADP Single Managers Conference ADP Conversion Cost

Randolph AFB Tx, 3-5 December 1975

2. Berg, John, L., editor

Data Base Directions - The Conversion Problem

NBS Special Publication 500-64, September 1980

3. Collica, Joseph, et al.

Conversion of Federal ADP Systems: A Tutorial

NBS Special Publication 500-62, August 1980

4. Computerworld

"Users Underestimate Conversion Costs : Survey"

October 8, 1979 p. 55

5. Conference Book of the National Symposium on Computer Systems Enhancement

Converting Today's Systems To Tomorrow's Technology

Data Processsing Management Association, November 13-15, 1979

6. Cooper, Roger

"Upgrading Federal Computers Through Existing Systems"

Government Executive, August 1979

7. Dooley, Ann

"Conversion Causes Welfare Payment Delays"

Computerworld, October 15, 1979

8. Federal Conversion Support Center

CONVERSION STUDY CHECKLIST

9. Federal Conversion Support Center

REVIEW AND ANALYSIS OF CONVERSION COST-ESTIMATING TECHNIQUES

Report No. GSA/FCSC-81/001, January 1981

10. Federal Information Processing Standard 43

Aids for COBOL Program Conversion (FIPS PUB 21 to FIPS PUB 21-1)

National Bureau of Standards, December 1, 1975

11. Fleiss, J., et al.

Programming for Transferability

Prepared for Rome Air Development Center, September 1972 
12. Frank, Werner L.

The New Software Economics

Library of Congress Catalog No. 79-90434, 1979

13. Fry, J., et al.

"An Assessment of the Technology for Data and ProgramRelated Conversion"

AFIPS Conference Proceedings

National Computer Conference, Anaheim, California, June 5-8, 1978

pp. $887-907$

14. GSG, Inc.

DPSC Experience Using the NAVDAC Conversion Management System

March 10, 1980

15. Headquarters, Department of the Army

Army Automation Planning Guide for Software Conversion

Department of the Army Technical Bulletin, October 1977

16. Lynn, C., et al.

"Program Conversion - One Successful Paradigm"

AFIPS Conference Proceedings, Volume 48

National Computer Conference, 1979

17. Morgan, L.W., et al.

Conversion of CCE UNIVAC Software

MITRE Corporation MTR-4710, January 1978

18. NTIS

Computer. Software Transferability and Portability

A Bibliography with Abstracts

NTIS/PS-79/0567, May 1979

19. Oliver, Paul

Bibliography of Conversion References

Federal COBOL Compiler Testing Service, April 4, 1978

20. Oliver, Paul

"Guidelines to Software Conversion"

AFIPS Conference Proceedings

National Computer Conference, Anaheim, California, June 5-8, 1978

pp. $877-886$

21. Oliver, Paul

Handbook for Estimating Conversion Costs of Large Business Programs

Department of the Navy, February 14, 1979

22. Oliver, Paul 
Survey of Conversion Support Sof tware

Federal COBOL Compiler Testing Service, March 16, 1978

23. Rand Information Systems

Conversion Special Report: Changing to New Technology

Commissioned by the Data Processing Management Association

Education Foundation for the National Symposium on Computer

Systems Enhancement, November 13-15, 1979

24. Rand Information Systems

Questions and Answers on Conversion

25. Razza, Sal

"Sof tware Portability"

Computerworld, November 19, 1979, p. 57

26. Schneider, Daniel B.

Computer Systems Conversion

A Management Perspective

U.S. Department of Justice, October 1978

27. Snider, Edward L., et al.

Data Processing Service Center Project Final Report

Naval Data Automation Command, December 1979

28. The Comptroller General of The United States

Report To The Congress

Contracting For Computer Software Development--Serious Problems

Require Management Attention To Avoid Wasting Additional

Millions

GAO FGMSD-80-4, November 9, 1979

29. The Comptroller General of The United States

Report To The Congress

Millions in Savings Possible in Converting Programs from One

Computer to Another

GAO FGMSD-77-34, September 15, 1977

30. The Comptroller General of the United States

Report To The Congress

The Federal Information Processing Standards Program: Many

Potential Benefits, Little Progress, and Many Problems

GAO FGMSD-78-23, April 19, 1978

31. US Army Computer Systems Support and Evaluation Agency

Survey of Software Conversion Aids (Emulators, Simulators, Translators)

1 December 1975

32. US General Accounting Office

PROVISIONAL CHECKLIST FOR SOFTWARE CONVERSION PROJECTS

September 15, 1977 

NBS-114A IREV. 2-AC)

\begin{tabular}{|c|c|c|c|}
\hline $\begin{array}{l}\text { U.S. OEPT. OF COMM. } \\
\text { BIBLIOGRAPHIC DATA } \\
\text { SHEET (See in structions) }\end{array}$ & $\begin{array}{l}\text { 1. PUBLICATION OR } \\
\text { REPORT NO. } \\
\text { NBS SP } 500-90\end{array}$ & 2. Performing Organ. Report No. & $\begin{array}{c}\text { 3. Publication Uate } \\
\text { May } 1982\end{array}$ \\
\hline \multicolumn{4}{|l|}{ 4. TITLE AND SUBTITLE } \\
\hline \multicolumn{4}{|l|}{$\begin{array}{l}\text { 5. AUTHOR(S) } \\
\text { Mark W. Ska11 }\end{array}$} \\
\hline \multicolumn{3}{|c|}{$\begin{array}{l}\text { 6. PERFORMING ORGANIZATION (If joint or other thon NBS, see in structions) } \\
\text { NATIONAL BUREAU OF STANDARDS } \\
\text { DEPARTMENT OF COMMERCE } \\
\text { WASHINGTON, D.C. } 20234\end{array}$} & $\begin{array}{l}\text { 7. Contract Grant No. } \\
\text { 8. Type of Report \& Period Covered } \\
\text { Final }\end{array}$ \\
\hline
\end{tabular}

10. SUPPLEMENTARY NOTES

Library of Congress Catalog Card Number: 82-600531

Document describes a computer program; SF-185, FIPS Software Summary, is attached.

11. ABSTRACT (A 200-word or less foctual summary of most significont information. If document includes a significant bibliography or literoture survey, mention it here)

This guide is the first in a series of publications which will be issued by the National Bureau of Standards with respect to conversion of Federal agency ADP systems. The need for these publications was determined by a study conducted in 1980, consisting of interviews with commercial conversion experts and Federal Government agency personnel who have recently experienced conversions, as well as a search of the current literature. The results of that study are documented in NBS Special Publication 500-62, entitled CONVERSION OF FEDERAL ADP SYSTEMS: A TUTORIAL. The purpose of this guide is to educate the Federal manager in the benefits which can be gained by contracting for conversion services as well as to specify all the actions the agency must take to ensure a successful conversion contract. The guide concludes that a smooth conversion can be accomplished by thoroughly planning the contractor's activities and effectively communicating triese plans to the contractor.

12. KEY WORDS (Six to twelve entries; alphobetical order; copitalize only proper names; and separate key words by semicolons) Acceptance tests; conversion contracting; conversion problems; deliverables; evaluation criteria; Federal agencies; language translators; portability; program inventory; RFP; statement of work

13. AVAILABILITY

[X] Unlimited

L. J For Official Distribution. Do Not Release to NTIS

[X. Order From Superintendent of Documents, U.S. Government Printing Office, Washington, D.C. 20402.

L.j.j Order From National Technical Information Service (NTIS), Springfield, VA, 2216I

14. NO. OF

PRINTED PAGES

67

15. Price 


\section{ANNOUNCEMENT OF NEW PUBLICATIONS ON COMPUTER SCIENCE \& TECHNOLOGY}

Superintendent of Documents, Government Printing Office,

Washington, D. C. 20402

Please add my name to the announcement list of new publications to be issued in the series: National Bureau of Standards Special Publication 500-.

Name

Company

Address

City State

Zip Code

(Notification key $\mathbf{N}-503$ ) 



\section{NBS TECHNICAL PUBLICATIONS}

\section{PERIODICALS}

JOURNAL OF RESEARCH-The Journal of Research of the National Bureau of Standards reports NBS research and development in those disciplines of the physical and engineering sciences in which the Bureau is active. These include physics, chemistry, engineering, mathematics, and computer sciences. Papers cover a broad range of subjects, with major emphasis on measurement methodology and the basic technology underlying standardization. Also included from time to time are survey articles on topics closely related to the Bureau's technical and scientific programs. As a special service to subscribers each issue contains complete citations to all recent Bureau publications in both NBS and nonNBS media. Issued six times a year. Annual subscription: domestic \$18: foreign \$22.50. Single copy; \$4.25 domestic: \$5.35 foreign.

\section{NONPERIODICALS}

Monographs-Major contributions to the technical literature on various subjects related to the Bureau's scientific and technical activities

Handbooks-Recommended codes of engineering and industrial practice (including safety codes) developed in cosperation with interested industries, professional organizations, and regulatory bodies.

Special Publications-Include proceedings of conferences sponsored by NBS, NBS annual reports, and other special publications appropriate to this grouping such as wall charts, pocket cards, and bibliographies.

Applied Mathematics Series-Mathematical tables, manuals, and studies of special interest to physicists, engineers, chemists, biologists, mathematicians, computer programmers, and others engaged in scientific and technical work.

National Standard Reference Data Series-Provides quantitative data on the physical and chemical properties of materials, compiled from the world's literature and critically evaluated. Developed under a worldwide program coordinated by NBS under the authority of the National Standard Data Act (Public Law 90-396).

NOTE: The principal publication outlet for the foregoing data is the Journal of Physical and Chemical Reference Data (JPCRD) published quarterly for NBS by the American Chemical Society (ACS) and the American Institute of Physics (AIP). Subscriptions, reprints, and supplements available from ACS, 1155 Sixteenth St. Niv. Washington, DC 20056
Building Science Series-Disseminates technical information developed at the Bureau on building materials, components, systems, and whole structures. The series presents research results, test methods, and performance criteria related to the structural and environmental functions and the durability and safety charac. teristics of building elements and systems.

Technical Notes-Studies or reports which are complete in themselves but restrictive in their treatment of a subject. A nalogous to monographs but not so comprehensive in scope or definitive in treatment of the subject area. Often serve as a vehicle for final reports of work performed at NBS under the sponsorship of other government agencies.

Voluntary Product Standards-Developed under procedures published by the Department of Commerce in Part 10, Title 15, of the Code of Federal Regulations. The standards establish nationally recognized requirements for products, and provide all concerned interests with a basis for common understanding of the characteristics of the products. NBS administers this program as a supplement to the activities of the private sector standardizing organizations.

Consumer Information Series-Practical information, based on NBS research and experience, covering areas of interest to the consumer. Easily understandable language and illustrations provide useful background knowledge for shopping in today's technological marketplace.

Order the above NBS publications from: Superintendent of Documents. Government Printing Office. Washington. DC 20402

Order the following NBS publications-FIPS and NBSIR"s-from the National Technical Information Services. Springfield. VA 22161.

Federal Information Processing Standards Publications (FIPS PUB)-Publications in this series collectively constitute the Federal Information Processing Standards Register. The Register serves as the official source of information in the Federal Government regarding standards issued by NBS pursuant to the Federal Property and Administrative Services Act of 1949 as amended. Public Law 89-306 (79 Stat. 1127), and as implemented by Ex. ecutive Order 11717 (38 FR 12315, dated May: 11, 1973) and Part 6 of Title 15 CFR (Code of Federal Regulations).

NBS Interagency Reports (NBSIR) - A special series of interim or final reports on work performed by NBS for outside sponsors (both government and non-government). In general, initial distribution is handled by the sponsor; pubic distribution is by the National Technical Information Services, Springfield. VA 22161, in paper copy or microfiche form. 
U.S. DEPARTMENT OF COMMERCE National Bureau of Standards

Washingtan, DC 20234

DFFICIAL BUSINESS

Penalty for Private Use, $\$ 300$
POSTAGE ANO FEES PAIO U.S: DEPARTMENT OF COMMEACE COM-215

THIRD CLASS 